\title{
Comprehensive Assessment of Mobile Service Privacy Security Based on FAHP and D-S Theory
}

\author{
Ming Yang $\mathbb{D}^{\mathbb{D}}$, Tilei Gao, Rong Jiang, Li Jia $\mathbb{D}$, and Di Yang \\ School of Information, Yunnan University of Finance and Economics, Kunming 650221, China \\ Correspondence should be addressed to Li Jia; 83300934@qq.com
}

Received 21 November 2021; Revised 19 January 2022; Accepted 27 January 2022; Published 23 February 2022

Academic Editor: Qiang Ye

Copyright (C) 2022 Ming Yang et al. This is an open access article distributed under the Creative Commons Attribution License, which permits unrestricted use, distribution, and reproduction in any medium, provided the original work is properly cited.

\begin{abstract}
As an indispensable medium for people's daily life and communication, mobile applications provide users with a variety of services. In order to enjoy these services, users inevitably need to provide personal privacy information or authorization to application providers in the process of use. In the case of insufficient privacy security evaluation, even if users use the applications verified by the application market, their privacy security will be threatened because of their weak awareness of privacy protection. Therefore, in order to ensure the privacy security of users, this paper establishes a mobile service assessment attribute model including 3 risk categories and 11 risk indicators. Based on this model, this paper proposes a service risk weight assessment method based on FAHP (fuzzy analytical hierarchy process), defines the risk level and its trust degree from two aspects of risk frequency and risk loss, and puts forward a reasonable fusion method for different assessment results of risk level based on D-S (Dempster-Shafer) theory, so as to realize the multidimensional and multilayer assessment of mobile service risk. Finally, the case analysis shows that the method proposed in this paper is reasonable and feasible and has important value for improving the security of mobile services and managing users' privacy information.
\end{abstract}

\section{Introduction}

According to global mobile market report of market research firm Newzoo [1], the number of global smartphone users has reached 3.9 billion. According to the survey of China Mobile Internet development report [2], the total number of mobile users in China has reached 1.289 billion, and the number of mobile applications has reached 3.45 million. Thus, it can be seen that, with the development of communication technology, mobile application has become an indispensable product for public life and has an extremely large user group all over the world.

However, with the gradual expansion of the application market, the problem of user privacy security is becoming more and more serious. At this stage, although many mobile application markets have carried out relevant security detection on their applications, these applications that have passed the detection still have potential threats to users' privacy security. According to the 2020 annual observation report on Internet mobile application privacy in China [3], more than $82.72 \%$ of the 3.3 million applications in China have vulnerability risk. These malicious applications mainly have a variety of malicious behaviors on mobile users, such as privacy data collection, malicious fee deduction, traffic resource consumption, system damage, and advertising push, which pose a great threat to the personal information and property security of mobile users. These privacy security problems not only come from technical vulnerabilities but also are affected by the service provider's operating environment, actual application scenarios, and terminal equipment risks.

Therefore, it is still not enough to ensure the privacy security of users in the use process only through the security detection of the application market. In order to ensure the privacy and security of users, in addition to solving technical problems, it is also necessary to sort out relevant risk indicators, establish a special assessment system, and provide users with comprehensive assessment results through evaluation, so as to help users reasonably select and use relevant services. In order to achieve this goal, aiming at 
multiple risk indicators of mobile service privacy risk, this paper establishes a risk attribute model based on FAHP (fuzzy analytical hierarchy process). FAHP is a method which is suitable to deal with multiobjective decisionmaking problems. The establishment of a hierarchical model based on FAHP can not only provide support for the assessment of privacy risk but also provide users with the weight comparison results of relevant risk indicators. On this basis, in order to solve the problem of conflict information in the assessment process and provide users with intuitive assessment results, this paper further assesses the level of risk combined with D-S (Dempster-Shafer) theory. $\mathrm{D}-\mathrm{S}$ theory is an uncertain reasoning method, which is suitable to deal with multi-information problems. It can reasonably solve the conflict information in the assessment process and effectively fuse the information. As mentioned above, the combination of FAHP and D-S theory can provide support for risk assessment and ensure the comprehensiveness and objectivity of assessment results. Therefore, this paper integrates the two theories into the assessment of mobile service privacy risk, establishes a mobile service privacy risk attribute model including 3 risk categories and 11 risk indicators, assesses the risk weight and risk level, and finally realizes the multilevel and multi-dimensional assessment of mobile service privacy risk.

This paper can divided into the following parts: in Section 1, this paper introduces the research background and content; in Section 2, this paper summarizes the relevant attributes and assessment methods of mobile service privacy risk and points out the problems existing in the current research; in Section 3, this paper establishes the privacy risk attribute model based on FAHP and puts forward the evaluation method of risk weight; in Section 4, this paper proposes a privacy risk assessment method based on the D-S theory; in Section 5, based on the research results in Sections 3 and 4, this paper proposes a comprehensive evaluation method of mobile service privacy risk; in Section 6, the proposed method is applied to a specific case for analysis and compared with other assessment methods; in Section 7, the authors summarize the research work of this paper and points out the future research direction.

\section{Related Research}

Mobile applications provide a variety of services for public travel, shopping, communication, and financial management. To enjoy these services, users need to provide personal privacy information or authorization to service providers. Through the research on mobile application recommendation service, Wang et al. [4] pointed out that how to protect users' privacy while ensuring high-precision recommendation has become the main challenge for the development of mobile commerce. Li et al. [5] pointed out that the factors affecting the privacy security of mobile services include access control, protocol and authentication, integrity verification, and encryption privacy protection and pointed out that a special privacy risk assessment system should be established. In order to evaluate the privacy risk of mobile services, different scholars have explored the evaluation of user privacy security from different angles. Naga et al. [6] have established a risk assessment model for Android applications, which can determine the risk and its level according to the requested permission set. Liu et al. [7] established a special tool to analyze the privacy information that may be collected by Android mobile advertising. Shrivastava and Kumar [8] have established special rules to identify the untrusted permissions and intentions of Android applications. Lo et al. [9] provide a user privacy analysis framework for Android platform to detect user privacy risks, so as to help users manage their privacy reasonably. Yüksel et al. [10] established a fuzzy risk reasoning system, which can score the risk for the functions of Android applications and provide risk analysis results for users before the installation of applications. Dehling et al. [11] assessed the "medical" and "health and fitness" applications on IOS and Android and evaluated the impact on information security and privacy according to the potential damage of information leakage, the potential damage of information loss, and the potential value of information to third parties. Chang et al. [12] realized the effective assessment of mobile applications privacy risk by setting a special data set. Belani et al. $[13,14]$ analyzed the "intention" of mobile applications and its impact on user privacy and proposed effective verification methods to help users reasonably select and install secure applications. These methods have carried out the assessment of user privacy security from different aspects based on technology, authority, intention or function, but they have not established a complete assessment system to comprehensively assess the privacy risk of mobile services.

Shirazi and Iqbal [15] took the community cloud in mobile commerce as the research object and pointed out that users' privacy security is affected by data encryption, intrusion detection, identity management, security perception, privacy protocol, and other factors. Ashibani and Mahmoud [16] pointed out that ensures the security of mobile applications need to pay more attention to the impact of relevant technologies, such as identity authentication, access control, data encryption, attack detection mechanism, user authentication and authorization. Gutierrez et al. [17] pointed out that advertisements in mobile application platforms are invasive to users' privacy and may forcibly obtain users' location and other information, posing a threat to users' privacy and security. Lee et al. [18] pointed out that locationbased services are an important cause of user privacy information disclosure.

In addition to the above risk factors, scholars also analyzed the channels causing user privacy disclosure. Schyff et al. [19] pointed out that the main reason for the disclosure of Facebook application privacy information is due to the application's monitoring and access to data. Bal et al. [20] pointed out that improving privacy risk communication on terminal devices can improve users' privacy security. Yang et al. [21] pointed out that there are great risks in the process of network transmission of users' privacy information. It can be seen that mobile services have potential privacy security risks in applications, network transmission, and terminal devices. 
For how to effectively evaluate privacy risk, Laleh et al. [22] put forward a new concept for risk measurement, that is, the greater the deviation between users' actual behavior and "normal behavior," the greater the risk. De and Métayer [23] discussed the concept of privacy risk from two aspects: damage and risk source of privacy risk and gave the corresponding privacy scoring mechanism to help users manage their privacy settings. Xiang [24] built a risk index system of personal privacy information disclosure of mobile commerce consumers and evaluated the risk of consumer privacy disclosure through the fuzzy comprehensive assessment method. Shi et al. [25], Zhang [26], and Yang [27] used the information entropy method to measure and assess the privacy risk according to the uncertainty of information. Ali-Eldin et al. [28] proposed a privacy risk assessment model, which can provide effective privacy risk avoidance and mitigation measures for open data. Cayirci [29] developed a prototype using machine learning to automatically analyze the risks of representative cloud service providers from the Cloud Security Alliance Security. In general, the privacy security of mobile services exists in different channels and is affected by many uncertain risk factors. To improve users' privacy security, we need to focus on the relevant risk factors and their loss impact, assess the privacy risk of mobile services from many aspects, and provide users with intuitive assessment results. The above assessment method solves the problem of privacy risk measurement, but it cannot effectively solve the problem of "conflict information" in the assessment process, nor comprehensively consider the assessment conclusions of different experts.

Therefore, in order to realize the comprehensive and effective assessment of mobile services, this paper intends to establish a multidimensional and multilevel assessment model combined with FAHP method and solve the problem of "conflict information" combined with fuzzy consistency matrix. On the other hand, this paper will describe the risk level combined with fuzzy theory and effectively integrate the assessment results of different experts according to D-S theory. Finally, through the combination of FAHP and D-S theory, this paper realizes the effective measurement and assessment of mobile service privacy risk and provides users with intuitive assessment results.

\section{Mobile Service Privacy Risk Weight Assessment Based on FAHP}

It is known that the publishing, management, and authorization of mobile services is a continuous interactive process, as shown in Figure 1.

The user's privacy information is accessed and used repeatedly in this interaction process, which is affected by various uncertain risk factors, resulting in users facing the risk of privacy information disclosure in every link of this interactive process. According to the interaction process shown in Figure 1, in order to assess the different dimensions of mobile services, this paper divides the privacy risk of mobile services into three risk categories. The meanings of these three risk categories are as follows:
(1) Platform risk $\beta_{1}$ refers to the privacy risk from platform operation management and functional services

(2) Network risk $\beta_{2}$ refers to the privacy risk in the process of network transmission

(3) Terminal risk $\beta_{3}$ refers to the privacy risk from user terminal equipment or terminal use scenarios

\subsection{Mobile Service Privacy Risk Attribute Model Based on} FAHP. Next, around the above three risk categories, this paper combines a total of 11 relevant risk factors through literature query and expert interview. The meaning of each risk factor $C_{i}$ is shown in Table $1(i=1,2, \ldots, 11)$.

After defining the above risk categories and risk indicators, this paper will assess the weight of mobile service privacy risk combined with the FAHP method. FAHP is known to be a qualitative and quantitative method, which is suitable for dealing with multiobjective decision-making problems.

To adopt the FAHP method, we first need to clarify the goal of decision-making and build its hierarchical model around the goal. When the hierarchical model is established, it is necessary to judge the weight of the elements on each layer relative to the elements on its upper layer, so as to realize the layer by layer assessment for the decision-making objectives. Therefore, considering that mobile service privacy risk is also a complex thing with multiple indicators, this paper establishes an attribute model of mobile service privacy risk combined with the FAHP method, so as to realize the multilevel and multidimensional assessment of mobile service privacy risk, as shown in Figure 2.

The model is divided into three dimensions (i.e., three risk categories) and three layers. The meaning of each layer in the model is as follows:

(1) Target layer: this layer is the target of the whole assessment, that is, the assessment of mobile service privacy security

(2) Scheme layer: this layer contains three risk categories $\beta_{j}$ to be assessed, $j=1,2,3$

(3) Indicator layer: this layer is composed of relevant indicators affecting the privacy security of mobile service, including 11 indicators $C_{i}, i=1,2, \ldots, 11$

The model is established to provide corresponding weight values for subsequent privacy risk level assessment. These weights include the assessment weight of each risk category $\beta_{j}$ relative to the whole service and the assessment weight of each indicator $C_{i}$ relative to different risk categories $\beta_{j}$. After calculating these weight values, combined with the subsequent risk level assessment, we can effectively realize the comprehensive assessment of mobile services from different angles and levels.

3.2. Risk Weight Assessment Based on Fuzzy Consistent Matrix. According to the method of AHP, when assessing the weight of the above risk categories $\beta_{j}$ and risk indicators 


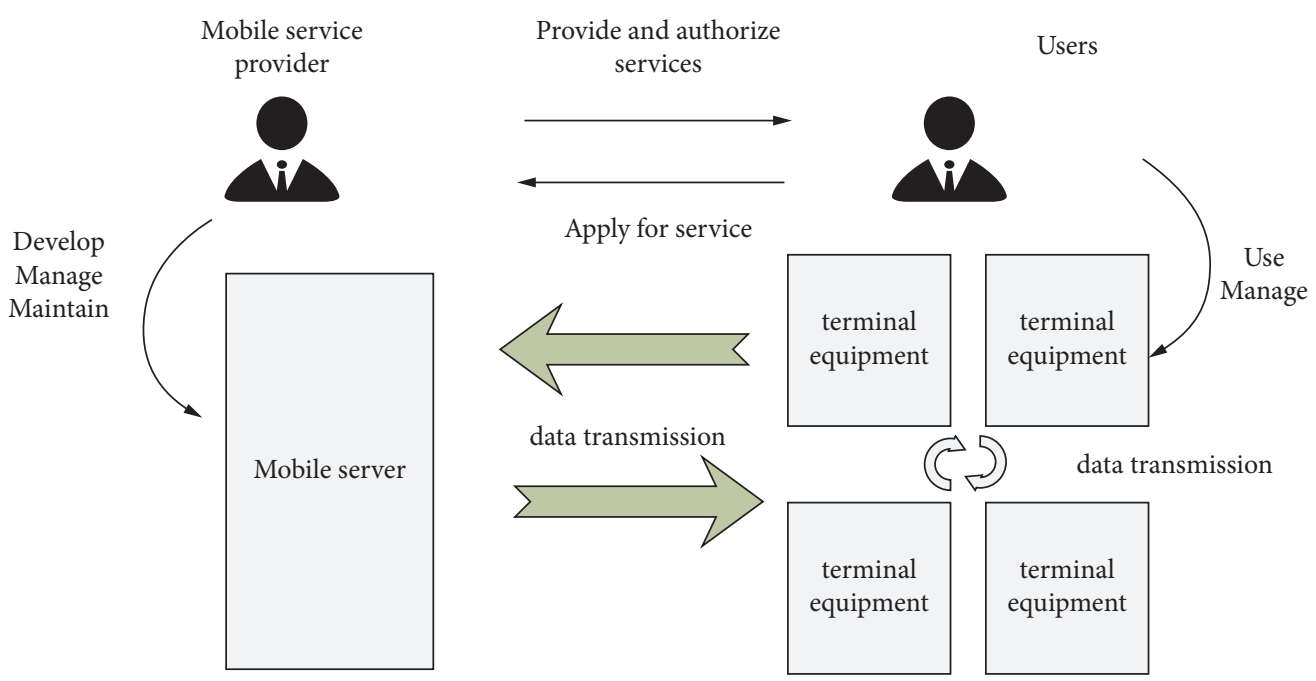

FIGURE 1: Interactive environment of mobile services.

TABLE 1: Mobile service privacy risk indicators.

\begin{tabular}{|c|c|c|}
\hline Indicators & Meaning & Example \\
\hline$C_{1}$ & Privacy disclosure risk caused by the behavior of internal malicious employees & Sell user information \\
\hline $\mathrm{C}_{2}$ & Privacy disclosure risk caused by the defects of the software itself & Virus threat \\
\hline$C_{3}$ & Risk of privacy information theft by mobile advertising & $\begin{array}{l}\text { Collect user preferences; track user } \\
\text { location }\end{array}$ \\
\hline$C_{4}$ & $\begin{array}{c}\text { Privacy disclosure risk caused by improper operation or service shutdown of } \\
\text { platform providers }\end{array}$ & Platform failure; service shutdown \\
\hline$C_{5}$ & $\begin{array}{c}\text { Privacy disclosure risk caused by server identity authentication and access rights } \\
\text { vulnerabilities }\end{array}$ & Unauthorized login; data isolation defect \\
\hline$C_{6}$ & $\begin{array}{l}\text { During the transmission of private information, privacy disclosure risk caused by } \\
\text { the vulnerability of encryption mechanism }\end{array}$ & $\begin{array}{l}\text { Insecure hotspot transmission and } \\
\text { Bluetooth connection }\end{array}$ \\
\hline$C_{7}$ & Privacy information disclosure caused by data loss of service providers & Mail loss; storage device loss \\
\hline$C_{8}$ & $\begin{array}{c}\begin{array}{c}\text { Privacy disclosure risk caused by loopholes in the operating system of terminal } \\
\text { equipment }\end{array}\end{array}$ & Trojan horse attack \\
\hline$C_{9}$ & Privacy disclosure risk caused by user rights management errors during use & Wrong authorization \\
\hline$C_{10}$ & Privacy disclosure risk caused by third-party application attacks during use & $\begin{array}{l}\text { Third party applications steal } \\
\text { information }\end{array}$ \\
\hline$C_{11}$ & Privacy disclosure risk caused by improper key management during use & Key loss; password setting is simple \\
\hline
\end{tabular}

$C_{i}$, it is necessary to compare the factor weights of each layer in the model shown in Figure 2 and build its weight judgment matrix relative to the factors of previous layer. It is assumed that there are $N$ factors to be evaluated in the assessment process. If these factors are compared in pairs, a total of $N(N-1) / 2$ judgments are required. When the value of $N$ is large, the expert needs to make more judgments, which is easy to cause inconsistency in the established judgment matrix. In addition, once the established judgment matrix is inconsistent, experts need to adjust the judgment until the matrix passes the consistency test.

So, if the traditional AHP method is used to assess the model shown in Figure 2, the assessment process will become particularly complex and difficult, and the accuracy of the final results will be affected. In order to solve this problem, this paper will use fuzzy consistency matrix to judge the weight. On the one hand, the fuzzy consistency matrix inherits the traditional AHP pairwise comparison method, which can reduce the impact of human subjective factors on the assessment results to a certain extent. On the other hand, it can effectively solve the inconsistency in the assessment process [30].

\subsubsection{The Construction of Fuzzy Consistency Matrix.} According to the definition of fuzzy consistency matrix [30], the weight ratio $\mu\left(C_{i}, C_{j}\right)$ between factor $u_{i}$ and factor $u_{j}$ has the following meanings:

(1) $\mu\left(u_{i}, u_{j}\right)=0.5$ means that $u_{i}$ and $u_{j}$ is equally important

(2) $0 \leq \mu\left(u_{i}, u_{j}\right)<0.5$ means that $u_{j}$ is more important than $u_{i}$, and the smaller the value of $\mu\left(u_{i}, u_{j}\right)$, the more important $u_{j}$ is than $u_{i}$

(3) $0.5<\mu\left(u_{i}, u_{j}\right) \leq 1$ means that $u_{i}$ is more important than $u_{j}$, and the larger the value of $\mu\left(u_{i}, u_{j}\right)$, the more important $u_{i}$ is than $u_{j}$ 


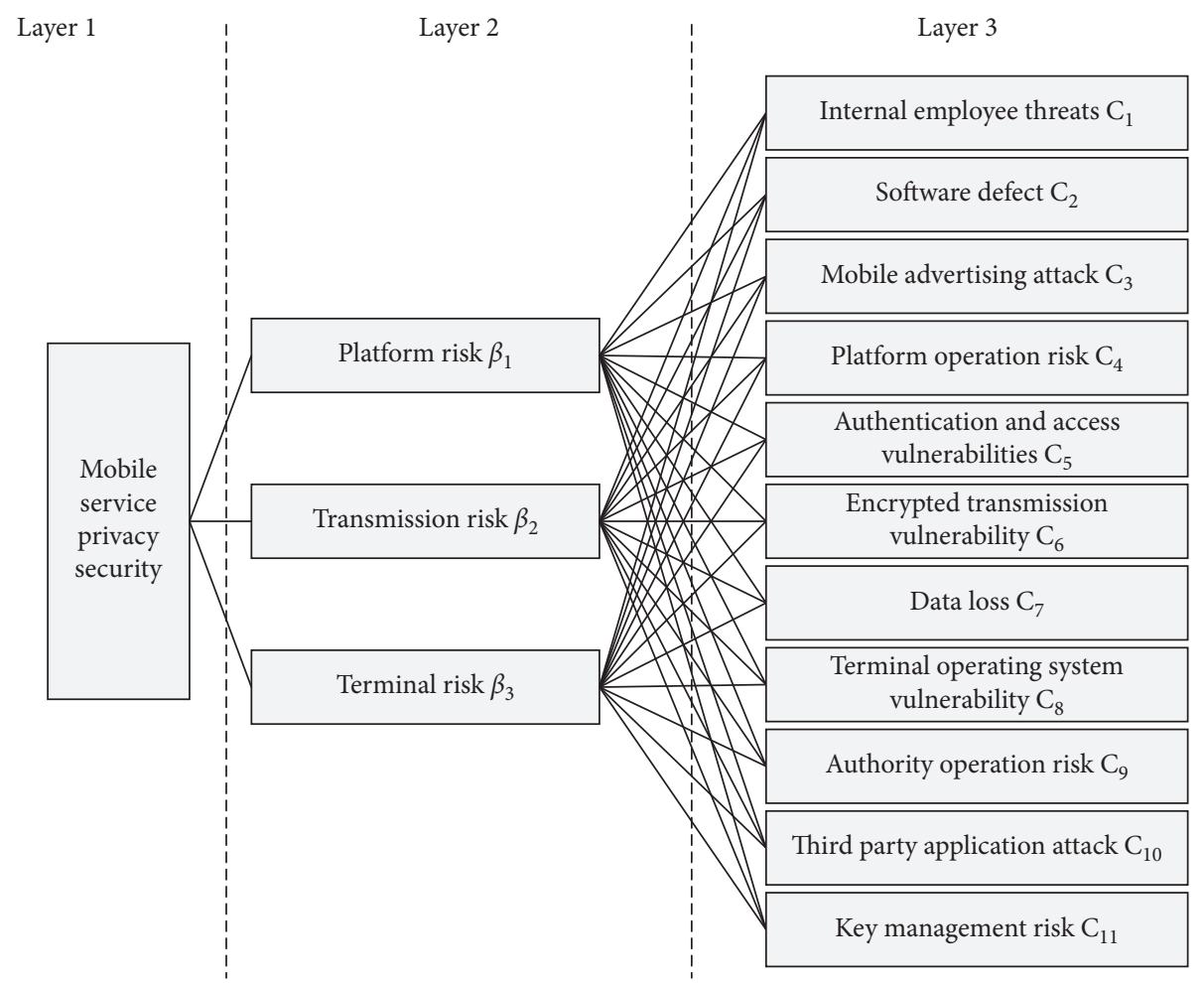

FIGURE 2: Risk attribute model of mobile service privacy based on FAHP.

Based on the above definition, this paper simplifies the construction of fuzzy consistency matrix into 3 steps, which are described as follows:

Step 1: construct the fuzzy judgment matrix between each factor: $\left(R_{i j}\right) n * n=\left|\begin{array}{ccc}\mu\left(u_{i}, u_{1}\right) & \ldots & \mu\left(u_{i}, u_{n}\right) \\ \ldots & \ldots & \ldots \\ \mu\left(u_{n}, u_{1}\right) & \ldots & \mu\left(u_{n}, u_{n}\right)\end{array}\right|$.

The matrix $\left(R_{i j}\right) n * n$ is a fuzzy matrix and does not have complete consistency.

Step 2: convert the established fuzzy matrix $\left(R_{i j}\right) n * n$ into a fuzzy consistency matrix according to the conversion formula:

$$
\underline{\mu}\left(u_{i}, u_{j}\right)=\frac{\sum_{l=1}^{n} \mu\left(u_{i}, u_{l}\right)}{\sum_{l=1}^{n}\left(\mu\left(u_{i}, u_{l}\right)+\mu\left(u_{j}, u_{l}\right)\right)} .
$$

Here, $\mu\left(u_{i}, u_{j}\right)$ represents the weight ratio between the two factors after transformation; thus, the new fuzzy consistency matrix is as follows:

$$
\left(\underline{R}_{i j}\right) n * n=\left|\begin{array}{ccc}
\underline{\mu}\left(u_{i}, u_{1}\right) & \ldots & \underline{\mu}\left(u_{i}, u_{n}\right) \\
\ldots & \ldots & \ldots \\
\underline{\mu}\left(u_{n}, u_{1}\right) & \ldots & \underline{\mu}\left(u_{n}, u_{n}\right)
\end{array}\right| .
$$

Different from the ordinary judgment matrix, the fuzzy consistency matrix $\left(\underline{R}_{i j}\right) n * n$ has complete consistency. Step 3: when the fuzzy consistency matrix $\left(\underline{R}_{i j}\right) n * n$ is obtained, the assessment weight of each factor can be calculated as follows.

$$
w_{i}=\frac{2 \sum_{j=1}^{n} \underline{\mu}\left(u_{i}, u_{j}\right)-1}{n(n-1)}, \quad i=1,2, \ldots, n
$$

$w_{i}$ represents the assessment weight value of factor $i$ in the matrix. According to the principle of FAHP's pairwise comparison method [31], $w_{i}$ has certain objectivity. The greater the value of $w_{i}$, the greater the influence weight of this factor on the assessment target.

3.2.2. The Fuzzy Consistency Matrix of Mobile Service Privacy Risk. Around the research goal of this paper, the model shown in Figure 2 is substituted into the steps in Section 3.2.1 for assessment. By constructing the following fuzzy consistency matrix layer by layer, the assessment weight of each risk category $\beta_{j}$ relative to the whole service and the assessment weight of each indicator $C_{i}$ relative to different risk categories $\beta_{j}$ all can be calculated, respectively:

(1) Weight judgment matrix of layer 2 relative to layer 1 The weight judgment matrix of layer 2 relative to layer 1 refers to the risk weight judgment matrix of each risk category $\beta_{j}$ relative to whole mobile service. By establishing the matrix, the assessment weight $W\left(\beta_{j}\right)$ of each risk category $\beta_{j}$ relative to the whole privacy risk can be calculated. The greater the value of $W\left(\beta_{j}\right)$, the greater the impact of risk category $\beta_{j}$ on the privacy risk of the whole mobile service. 
(2) Weight judgment matrix of layer 3 relative to layer 2 The weight judgment matrix of layer 3 relative to layer 2 includes three matrices, which are each indicator $C_{i}$ relative to risk category $\beta_{1}$, and each indicator $C_{i}$ is relative to the risk category $\beta_{2}$, and the weight judgment matrix of each indicator $C_{i}$ relative to the risk category $\beta_{3}$. Similarly, by establishing these three matrices, we can calculate the assessment weight $W\left(C_{i}, \beta_{j}\right)$ of indicator $C_{i}$ relative to risk category $\beta_{j}$. The greater the value of $W\left(C_{i}, \beta_{j}\right)$, the greater the impact of indicator $C_{i}$ on risk category $\beta_{j}$.

After calculating the assessment weight of $W\left(C_{i}, \beta_{j}\right)$ and $W\left(\beta_{j}\right)$ through the above method, combined with the risk level of each risk indicator $C_{i}$ at the bottom of the model shown in Figure 2, the multilevel and multidimensional assessment of mobile service risk can be realized from bottom to top. Therefore, next, this paper will continue to focus on the assessment of mobile service risk level.

\section{The Measurement of Privacy Risk Level of Mobile Services}

The privacy risk weight assessment of mobile services based on FAHP can only assess the degree of risk importance. To provide detailed assessment data for the selection and use of mobile services, we need to further assess the level of risk.

\subsection{Definition of Privacy Risk Level of Mobile Services.} Privacy risk is an abstract concept. In order to measure its level effectively, this paper preliminarily sets its risk level from two aspects: risk frequency and risk loss, as shown in Table 2.

\subsection{Risk Level Assessment Based on Fuzzy Theory and D-S} Theory. Although Table 2 defines the risk level from the perspectives of risk occurrence frequency and loss severity, due to the abstract characteristics of risk itself, it is still difficult for experts to clearly define its level in the actual assessment process.

In addition, in the assessment process, due to the influence of human factors, different experts will have some differences on the definition of risk level, which brings difficulties to the assessment process. To solve the above two problems, this paper proposes to redescribe the risk level combined with fuzzy theory [32] and fuse the assessment results of different experts with $\mathrm{D}-\mathrm{S}$ theory.

$\mathrm{D}-\mathrm{S}$ evidence theory is an uncertain reasoning method, which is often used in the field of information fusion. It can effectively deal with the problem of information conflict in the fusion process and can give a reasonable fusion result through calculation. In the fusion process, when there are multiple valid data, according to D-S theory, the first thing to do is to treat the collected data as valid evidence and then give each evidence with a trust degree. When each evidence has a trust degree, they can be fused through relevant formulas.

Therefore, in order to effectively integrate the risk level assessment results of each expert, according to D-S theory, this paper regards the assessment results of each expert as effective evidence and assesses the privacy risk level of mobile services. The process is as follows.

Firstly, in order to ensure the accuracy of the assessment results, based on the risk level shown in Table 2, this paper introduces the concept of trust degree $m(A)$, which is used to describe the level of privacy risk, $0 \leq m(A) \leq 1$. $A$ is a fuzzy set, which represents any possible set of the risk indicator level, including $\{1\},\{2\},\{3\},\{4\},\{1,2\},\{2,3\},\{3,4\}$, and $\sum_{A \neq \varnothing} m(A)=1$. As shown in Table 3 , the greater the value of $m(A)$, the greater the possibility that the risk indicator level belongs to set $A$.

Table 3 contains the assessment data of three experts on risk indicator $C_{i}$, namely, assessment 1 , assessment 2 , and assessment 3 . The three experts gave different trust degrees $m_{1}\left(A_{1}\right), m_{2}\left(A_{2}\right)$, and $m_{3}\left(A_{3}\right)$ for the occurrence frequency level of risk indicator $C_{i}$. In order to obtain an accurate assessment result, the assessment data of three experts need to be fused according to D-S theory [33].

$$
\begin{aligned}
m(A) & =\left(m_{1} \oplus m_{2} \oplus \cdots \oplus m_{n}\right)(A) \\
& =\frac{1}{k} \sum_{A_{1} \cap A_{2} \cap \ldots \cap A_{n}=A} m_{1}\left(A_{1}\right) m_{2}\left(A_{2}\right) \cdots m_{n}\left(A_{n}\right) .
\end{aligned}
$$

Here, $k$ is the normalization factor, and it has two calculation methods. The purpose of the two calculation methods is the same, and the results are the same, but the calculation methods are different, as shown in formulas (5) and (6).

$$
\begin{gathered}
k=1-\sum_{A_{1} \cap A_{2} \cap \ldots \cap A_{n}=\varnothing} m_{1}\left(A_{1}\right) m_{2}\left(A_{2}\right) \cdots m_{n}\left(A_{n}\right), \\
k=\sum_{A_{1} \cap A_{2} \cap \ldots \cap A_{n} \neq \varnothing} m_{1}\left(A_{1}\right) m_{2}\left(A_{2}\right) \cdots m_{n}\left(A_{n}\right) .
\end{gathered}
$$

As shown in Table 3, to fuse the assessment results of different experts, there are many possible sets to be analyzed, which bring difficulties to the calculation process. In order to simplify the calculation process, according to the basic idea of D-S approximate calculation, this paper proposes to use Bayes approximation method [34] to simplify set $A$ in $\mathrm{Ta}-$ ble 3 , and its calculation is shown in as follows:

$$
m(\underline{A})=\frac{\sum_{\underline{A} \subseteq A} m(A)}{\sum_{A \subseteq \Theta} m(A) * N} .
$$

Here, $\underline{A}$ is the simplified set of $A, \Theta$ represents the complete set, and $N$ is the total number of factors contained in A. As described above, the data in Table 3 can be substituted into formula (7) for calculation, and the calculation process is as follows: 
TABLE 2: Definition of privacy risk level of mobile services.

\begin{tabular}{|c|c|}
\hline $\begin{array}{l}\text { Risk frequency } \\
\text { level }\end{array}$ & Meaning \\
\hline 1 & This risk rarely occurs and is extremely rare \\
\hline 2 & This risk occurs occasionally and in rare cases \\
\hline 3 & This risk is a common risk and often occurs \\
\hline 4 & This risk is almost inevitable \\
\hline Risk loss level & Meaning \\
\hline 1 & This risk will hardly pose a threat to the privacy and security of users \\
\hline 2 & This risk will lead to the disclosure of users' basic information, such as interests, hobbies, and location information \\
\hline 3 & $\begin{array}{c}\text { This risk will cause the disclosure of important information of users, such as identity information, contact information, } \\
\text { and health information }\end{array}$ \\
\hline 4 & $\begin{array}{c}\text { This risk will lead to the disclosure of all users' privacy information, including key information, and financial } \\
\text { information }\end{array}$ \\
\hline
\end{tabular}

TABle 3: Frequency level of risk indicator $C_{i}$ based on fuzzy theory.

\begin{tabular}{lccc}
\hline $\begin{array}{l}\text { Risk frequency level } \\
\text { Arbitrary set } A\end{array}$ & $\begin{array}{c}\text { Assessment } 1 \\
m_{1}\left(A_{1}\right)\end{array}$ & $\begin{array}{c}\text { Assessment } 2 \\
m_{2}\left(A_{2}\right)\end{array}$ & $\begin{array}{c}\text { Assessment } 3 \\
m_{3}\left(A_{3}\right)\end{array}$ \\
\hline 1 & 0 & 0 & 0 \\
$1-2$ & 0 & 0 & 0 \\
2 & 0 & 0 & 0 \\
$2-3$ & 0.2 & 0.2 & 0.3 \\
3 & 0 & 0.7 & 0 \\
$3-4$ & 0.8 & 0 & 0.7 \\
4 & 0 & 0 & 0 \\
\hline
\end{tabular}

$$
\begin{aligned}
& m(\underline{1})=\frac{m(1)+m(1,2)}{m(1)+m(1,2) * 2+m(2)+m(2,3) * 2+m(3)+m(3,4) * 2+m(4)} \\
& m(\underline{2})=\frac{m(1,2)+m(2)+m(2,3)}{m(1)+m(1,2) * 2+m(2)+m(2,3) * 2+m(3)+m(3,4) * 2+m(4)} \\
& m(\underline{3})=\frac{m(2,3)+m(3)+m(3,4)}{m(1)+m(1,2) * 2+m(2)+m(2,3) * 2+m(3)+m(3,4) * 2+m(4)} \\
& m(\underline{4})=\frac{m(3,4)+m(4)}{m(1)+m(1,2) * 2+m(2)+m(2,3) * 2+m(3)+m(3,4) * 2+m(4)}
\end{aligned}
$$

Finally, the simplified set $A$ can be obtained, as shown in Table 4.

When the data in Table 4 are obtained, the normalization factor $k$ can be obtained more quickly by substituting the data in Table 4 into formula (6) compared with formula (5). Therefore, the trust degree $m(\underline{A})$ after fusion can be calculated by formulas (4) and (6), and the results are shown in Table 5 .

In Table $5, m(3)>m(4)>m(2)>m(1)$ shows that the occurrence frequency level of $C_{i}$ is most likely to belong to level 3, and the possibility of belonging to level 1 is the lowest. According to the same method, according to the same method, the trust degree of the loss level about $C_{i}$ can be obtained.

To sum up, combined with fuzzy theory this paper describes the privacy risk level of indicator $C_{i}$ from the perspectives of risk occurrence frequency and risk loss and puts forward an effective fusion method of expert assessment results combined with D-S theory.

\section{Comprehensive Assessment of Mobile Services Privacy Risk}

5.1. Process of the Comprehensive Assessment. Through the previous research, this paper proposes an effective risk weight assessment method based on FAHP model and fuzzy consistency matrix and proposes an effective privacy risk level assessment method based on D-S theory. By combining the above two theories, this paper realizes the comprehensive assessment of mobile service privacy risk. The process is shown in Figure 3.

As shown in Figure 3, the whole process is based on the attribute model of privacy risk. When the risk frequency fuzzy level $f\left(C_{i}\right)$ and risk loss fuzzy level $l\left(C_{i}\right)$ are obtained, 
TABle 4: Frequency level of risk indicator $C_{i}$ after Bayes approximation.

\begin{tabular}{lccc}
\hline $\begin{array}{l}\text { Risk frequency level } \\
\text { Arbitrary set } \underline{A}\end{array}$ & $\begin{array}{c}\text { Assessment } 1 \\
m_{1}\left(\underline{A}_{1}\right)\end{array}$ & $\begin{array}{c}\text { Assessment } 2 \\
m_{2}\left(\underline{A}_{2}\right)\end{array}$ & $\begin{array}{c}\text { Assessment } 3 \\
m_{3}\left(\underline{A}_{3}\right)\end{array}$ \\
\hline 1 & 0.0000 & 0.0000 & 0.0000 \\
2 & 0.1000 & 0.1053 & 0.1500 \\
3 & 0.5000 & 0.5263 & 0.5000 \\
4 & 0.4000 & 0.3684 & 0.3500 \\
\hline
\end{tabular}

TABle 5: The assessment results of $\underline{A}$ after D-S fusion.

\begin{tabular}{ll}
\hline Arbitrary set $\underline{A}$ & $m(\underline{A})$ \\
\hline 1 & 0.0000 \\
2 & 0.0085 \\
3 & 0.7123 \\
4 & 0.2792 \\
\hline
\end{tabular}

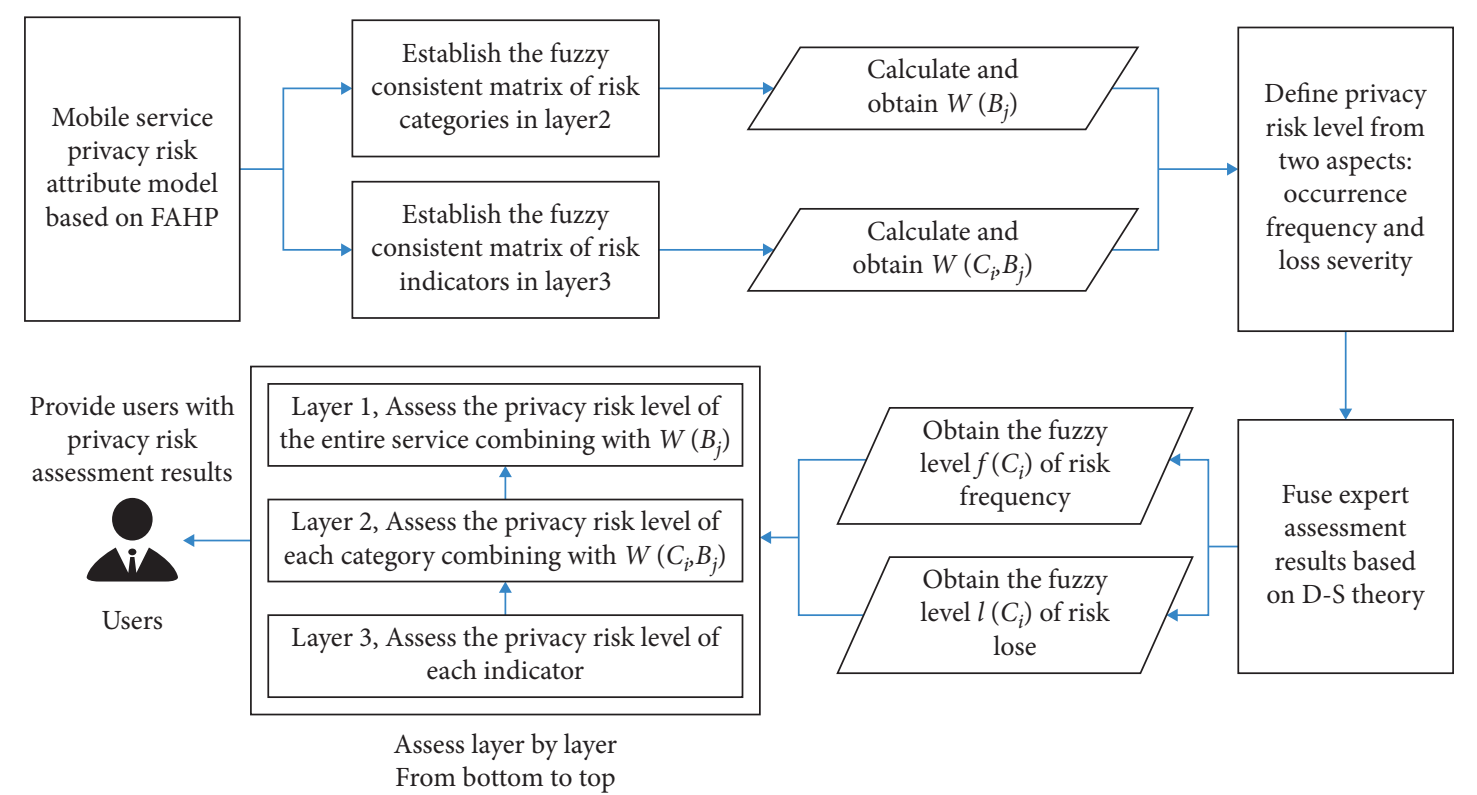

Figure 3: Comprehensive assessment of mobile service privacy risk.

combined with the weight assignment method proposed in Section 3, the whole mobile service can be assessed layer by layer from bottom to top.

5.1.1. Assessment on Layer 3. First, calculate the privacy risk level of indicators $C_{i}$ in layer3, and its calculation formula is as follows.

$$
\operatorname{lev}\left(C_{i}\right)=f\left(C_{i}\right) * l\left(C_{i}\right)
$$

Here, $f\left(C_{i}\right)$ represents the risk frequency level of indicator $C_{i}$, and $l\left(C_{i}\right)$ represents the risk loss level of indicator $C_{i}$. According to the definition of risk matrix method, the privacy risk level lev $\left(C_{i}\right)$ of indicator $C_{i}$ can be obtained by multiplying $f\left(C_{i}\right)$ and $l\left(C_{i}\right)$, as shown in Table 6 .
In Table 6, $\{$ I, II, III, IV $\}$, respectively, represent the privacy risk level of mobile services. Level I indicates that the indicator or service is secure, and there is almost no privacy security problem; Level II indicates that the indicator or service is relatively secure, and there are certain privacy security problems, which may cause the disclosure of users' basic information, such as location information and interest preferences; Level III indicates that the indicator or service is unsafe and there are major privacy security problems, which will cause the disclosure of important information of users, such as identity information, contact information, and health information; Level IV indicates that the indicator or service is extremely dangerous and has a very large privacy security problem, which will lead to the disclosure of users' key privacy information, such as financial information and key information. 
Table 6: Privacy risk classification matrix of mobile services.

\begin{tabular}{|c|c|c|c|c|}
\hline \multirow{2}{*}{ Risk frequency level } & \multicolumn{4}{|c|}{ Loss severity level } \\
\hline & 1 & 2 & 3 & 4 \\
\hline 4 & $4 / \mathrm{II}$ & $8 / \mathrm{III}$ & $12 / \mathrm{IV}$ & $16 / \mathrm{IV}$ \\
\hline 3 & $3 / \mathrm{I}$ & 6/II & 9/III & $12 / \mathrm{IV}$ \\
\hline 2 & $2 / \mathrm{I}$ & $4 / \mathrm{I}$ & $6 / \mathrm{II}$ & 8/III \\
\hline 1 & $1 / \mathrm{I}$ & $2 / \mathrm{I}$ & $3 / \mathrm{I}$ & $4 / \mathrm{II}$ \\
\hline
\end{tabular}

5.1.2. Assessment on Layer 2. According to the risk attribute model shown in Figure 2, when $f\left(C_{i}\right)$ and $l\left(C_{i}\right)$ of the risk indicator in layer 3 are calculated, combined with the assessment weight $W\left(C_{i}, \beta_{j}\right)$ in Section 3.2, the privacy risk level lev $\left(\beta_{j}\right)$ of risk categories can be calculated, as follows.

$$
\operatorname{lev}\left(\beta_{j}\right)=f\left(\beta_{j}\right) * l\left(\beta_{j}\right)=\left\{\sum_{i=1}^{11} f\left(C_{i}\right) * W\left(C_{i}, \beta_{j}\right)\right\} *\left\{\sum_{i=1}^{11} l\left(C_{i}\right) * W\left(C_{i}, \beta_{j}\right)\right\}
$$

5.1.3. Assessment on Layer 1. According to the risk attribute model shown in Figure 2, after calculating the $f\left(\beta_{j}\right)$ and $l\left(\beta_{j}\right)$ of risk categories in layer 2 , combined with the assessment weight $W\left(\beta_{j}\right)$, the privacy risk level of the whole service can be calculated, as follows.

lev $=\left\{\sum_{j=1}^{3} f\left(\beta_{j}\right) * W\left(\beta_{j}\right)\right\} *\left\{\sum_{j=1}^{3} l\left(\beta_{j}\right) * W\left(\beta_{j}\right)\right\}$.

In formula (11), lev represents the privacy risk level of the entire mobile service.

\subsection{Representation of the Assessment Result Based on Fuzzy} Theory. In order to more objectively describe the privacy risk level of mobile services, combined with fuzzy theory, this paper redescribes the privacy risk level, as shown in Figure 4.

In Figure 4, the privacy risk level is represented as a triangular value [35], lev $=\left\{l e v^{\text {lower }}, l e v^{\max }, l e v^{\text {upper }}\right\}$. Among them, $l e v^{\text {lower }}$ represents the lower limit of risk level about a factor or service, $l e v^{\text {upper }}$ represents the upper limit of risk level about a factor or service, and $l e v^{\max }$ represents the maximum trust risk level of a factor or service. As mentioned above, the following formulas can be obtained by changing formulas (9)-(11) based on fuzzy theory.

$$
\begin{aligned}
l e v^{\text {upper }}\left(C_{i}\right) & =f^{\text {upper }}\left(C_{i}\right) * l^{\text {upper }}\left(C_{i}\right), \\
\text { lev } v^{\text {lower }}\left(C_{i}\right) & =f^{\text {lower }}\left(C_{i}\right) * l^{\text {lower }}\left(C_{i}\right), \\
l e v^{\max }\left(C_{i}\right) & =f^{\max }\left(C_{i}\right) * l^{\max }\left(C_{i}\right) .
\end{aligned}
$$

In formula (12), $f^{\max }\left(C_{i}\right)$ is the maximum trust risk frequency level of indicator $C_{i}, f^{\text {upper }}\left(C_{i}\right)$ is the maximum risk frequency level of indicator $C_{i}, f^{\text {lower }}\left(C_{i}\right)$ is the minimum risk frequency level of indicator $C_{i} . l^{\max }\left(C_{i}\right)$ is the maximum trust risk loss level of indicator $C_{i}, l^{\text {upper }}\left(C_{i}\right)$ is the maximum risk loss level of indicator $C_{i}$, and $l^{\text {lower }}\left(C_{i}\right)$ is the minimum risk loss level of indicator $C_{i}$.

$$
\begin{aligned}
\text { lev }^{\text {upper }}\left(\beta_{j}\right) & =f^{\text {upper }}\left(\beta_{j}\right) * l^{\text {upper }}\left(\beta_{j}\right) \\
& =\left\{\sum_{i=1}^{11} f^{\max }\left(C_{i}\right) * W\left(C_{i}, \beta_{j}\right)\right\} *\left\{\sum_{i=1}^{11} l^{\max }\left(C_{i}\right) * W\left(C_{i}, \beta_{j}\right)\right\}, \\
\text { lev }^{\text {lower }}\left(\beta_{j}\right) & =f^{\text {lower }}\left(\beta_{j}\right) * l^{\text {lower }}\left(\beta_{j}\right) \\
& =\left\{\sum_{i=1}^{11} f^{\text {lower }}\left(C_{i}\right) * W\left(C_{i}, \beta_{j}\right)\right\} *\left\{\sum_{i=1}^{11} l^{\text {lower }}\left(C_{i}\right) * W\left(C_{i}, \beta_{j}\right)\right\}, \\
\text { lev }^{\max }\left(\beta_{j}\right) & =f^{\max }\left(\beta_{j}\right) * l^{\max }\left(\beta_{j}\right) \\
& =\left\{\sum_{i=1}^{11} f^{\max }\left(C_{i}\right) * W\left(C_{i}, \beta_{j}\right)\right\} *\left\{\sum_{i=1}^{11} l^{\max }\left(C_{i}\right) * W\left(C_{i}, \beta_{j}\right)\right\} .
\end{aligned}
$$

In formula (13), $f^{\max }\left(\beta_{j}\right)$ is the maximum trust risk frequency level of risk category $\beta_{j}, f^{\text {upper }}\left(\beta_{j}\right)$ is the maximum risk frequency level of risk category $\beta_{j}$, and $f^{\text {lower }}\left(\beta_{j}\right)$ is the minimum risk frequency level of risk 


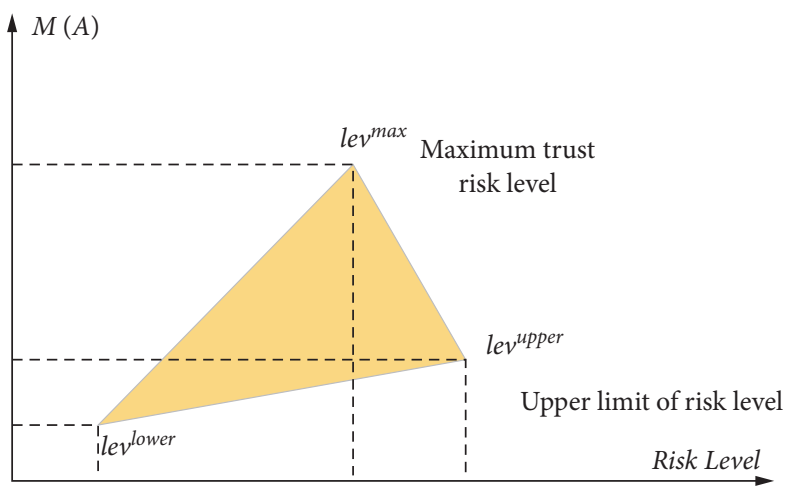

Lower limit of risk level

FIgURE 4: Risk level description based on fuzzy theory.

category $\beta_{j} . l^{\max }\left(\beta_{j}\right)$ is the maximum trust risk loss level of risk category $\beta_{j}$, lupper $\left(\beta_{j}\right)$ is the maximum risk loss level of risk category $\beta_{j}$, and $l^{\text {lower }}\left(\beta_{j}\right)$ is the minimum risk loss level of risk category $\beta_{j}$.

$$
\begin{aligned}
\text { lev } \text { upper }\left(C_{i}\right) & =\left\{\sum_{j=1}^{3} f^{\text {upper }}\left(\beta_{j}\right) * W\left(\beta_{j}\right)\right\} *\left\{\sum_{j=1}^{3} l^{\text {upper }}\left(\beta_{j}\right) * W\left(\beta_{j}\right)\right\}, \\
\text { lev } & \text { max }\left(C_{i}\right)=\left\{\sum_{j=1}^{3} f^{\max }\left(\beta_{j}\right) * W\left(\beta_{j}\right)\right\} *\left\{\sum_{j=1}^{3} l^{\max }\left(\beta_{j}\right) * W\left(\beta_{j}\right)\right\}, \\
\text { lev }{ }^{\text {lower }}\left(C_{i}\right) & =\left\{\sum_{j=1}^{3} f^{\text {lower }}\left(\beta_{j}\right) * W\left(\beta_{j}\right)\right\} *\left\{\sum_{j=1}^{3} l^{\text {lower }}\left(\beta_{j}\right) * W\left(\beta_{j}\right)\right\} .
\end{aligned}
$$

Using the above triangular fuzzy value to represent the level of privacy risk, which is more objective than the method of "using only one fixed value to represent the risk level."

\section{Case Analysis}

In order to verify the feasibility of the proposed method, this paper assesses two mobile service providers, respectively. The first is a mobile application service provider focusing on takeout and group purchase, and the second is a mobile application service provider focusing on financial investment and wealth management. Through investigation, around the risk attribute model in Figure 2, this paper summarizes the privacy risk characteristics of the two mobile services, as shown in Table 7.

\subsection{Analysis Process}

6.1.1. Risk Assessment Weight Calculation. Firstly, based on the model in Figure 2, using the method proposed in Section 3 , this paper establishes the relevant fuzzy consistency matrix layer by layer and calculates the correlation matrix according to formula (3) and obtains the assessment weight of each indicator and risk category, as shown in Table 8.
6.1.2. Risk Level Assessment. After calculating the assessment weight of each risk indicator and risk category, this paper convened three experts in the field to assess the risk level of each risk indicator according to the method shown in Section 4.2. The risk level assessment distribution results of each risk indicator of Company 1 are shown in Tables 9 and 10.

According to the method proposed in Section 4 of this paper, the data of Tables 9 and 10 are simplified by Bayes approximation, and then the simplified results are fused in combination with $\mathrm{D}-\mathrm{S}$ theory. The fused results are shown in Tables 11 and 12 .

6.1.3. Comparative Analysis of Assessment Results Layer by Layer. According to the method in this paper, through substituting the above results into formulas (12)-(14), the mobile service privacy risk assessment results of Company 1 can be calculated. Similarly, this paper also assesses the mobile service of Company 2. Finally, this paper compares the privacy risk assessment results of the two companies layer by layer.

(1) Risk Level Comparison in the 3rd Layer. According to the result expression method in Section 5.2, the risk level of each indicator in layer 3 is expressed as 
TABle 7: Privacy risk characteristics of the two services.

\begin{tabular}{|c|c|c|}
\hline & Company A & Company B \\
\hline $\begin{array}{l}\text { Internal employee } \\
\text { threats }\end{array}$ & $\begin{array}{c}\text { There have been many disciplinary violations by } \\
\text { internal employees }\end{array}$ & $\begin{array}{l}\text { The internal employees of the service provider only } \\
\text { master the basic information of users, and there are no } \\
\text { reports of discipline violations by employees }\end{array}$ \\
\hline Software defect & $\begin{array}{l}\text { It can pass the detection of relevant security detection } \\
\text { tools without obvious technical loopholes }\end{array}$ & $\begin{array}{l}\text { It can pass the detection of relevant security detection } \\
\text { tools without obvious technical loopholes }\end{array}$ \\
\hline $\begin{array}{l}\text { Mobile advertising } \\
\text { attack }\end{array}$ & $\begin{array}{l}\text { Contains a large number of personalized } \\
\text { recommendation advertisements }\end{array}$ & $\begin{array}{c}\text { Contains a small amount of financial recommendation } \\
\text { advertising }\end{array}$ \\
\hline Platform operation risk & $\begin{array}{c}\text { The platform has been in stable operation for } 10 \text { years, } \\
\text { and the service shutdown will not pose a serious privacy } \\
\text { threat to users }\end{array}$ & $\begin{array}{c}\text { The platform has been operating stably for more than } \\
20 \text { years, and the service shutdown will pose a serious } \\
\text { threat to user privacy }\end{array}$ \\
\hline $\begin{array}{l}\text { Authentication and } \\
\text { access vulnerabilities }\end{array}$ & $\begin{array}{l}\text { No real name authentication is required to use this } \\
\text { service. You can directly authorize login with mobile } \\
\text { phone verification code or third-party application. }\end{array}$ & $\begin{array}{l}\text { Using this service requires real name authentication } \\
\text { and bank card binding authentication, and the service } \\
\text { has strict access control }\end{array}$ \\
\hline $\begin{array}{l}\text { Encrypted transmission } \\
\text { vulnerability }\end{array}$ & $\begin{array}{l}\text { The user's privacy information is encrypted and } \\
\text { anonymized, and the user's contact information, } \\
\text { address, and other information will be exposed during } \\
\text { the transaction }\end{array}$ & $\begin{array}{l}\text { The user information is encrypted, and the user } \\
\text { information will not be exposed during the transaction }\end{array}$ \\
\hline Data loss & $\begin{array}{l}\text { There are reports of user data loss. In the process of } \\
\text { transaction, user data may be lost. }\end{array}$ & $\begin{array}{l}\text { There are special transaction records and notary } \\
\text { institutions, and there is almost no possibility of user } \\
\text { data loss using this service }\end{array}$ \\
\hline $\begin{array}{l}\text { Terminal operating } \\
\text { system vulnerability }\end{array}$ & $\begin{array}{l}\text { The application has low requirements for terminal } \\
\text { configuration, and the terminal hardware used in the } \\
\text { test has no obvious vulnerabilities }\end{array}$ & $\begin{array}{l}\text { The application has high requirements for terminal } \\
\text { configuration, and the terminal hardware used in the } \\
\text { test has no obvious vulnerabilities }\end{array}$ \\
\hline $\begin{array}{l}\text { Authority operation } \\
\text { risk }\end{array}$ & $\begin{array}{c}\text { It includes access to location, phone, camera, address } \\
\text { book, storage and motion data }\end{array}$ & $\begin{array}{l}\text { Including access to location, phone, camera, and } \\
\text { storage }\end{array}$ \\
\hline $\begin{array}{l}\text { Third party application } \\
\text { attack }\end{array}$ & $\begin{array}{l}\text { There is information association and authorization } \\
\text { cooperation with third-party applications }\end{array}$ & There is no association with third-party applications \\
\hline Key management risk & $\begin{array}{l}\text { There is a simple payment password, which can be } \\
\text { modified with the mobile phone verification code }\end{array}$ & $\begin{array}{c}\text { The password security level is high, and there are strict } \\
\text { key management measures }\end{array}$ \\
\hline
\end{tabular}

TABLE 8: The assessment weight of risk indicators and risk classes.

\begin{tabular}{lccc}
\hline & $\beta_{1}$ & $\beta_{2}$ & $\beta_{3}$ \\
\hline$W\left(\beta_{j}\right)$ & 0.377 & 0.280 & 0.343 \\
\hline$C_{1}$ & $W\left(C_{i}, \beta_{1}\right)$ & $W\left(C_{i}, \beta_{2}\right)$ & $W\left(C_{i}, \beta_{3}\right)$ \\
$C_{2}$ & 0.101 & 0.080 & 0.071 \\
$C_{3}$ & 0.114 & 0.103 & 0.086 \\
$C_{4}$ & 0.112 & 0.089 & 0.100 \\
$C_{5}$ & 0.102 & 0.075 & 0.061 \\
$C_{6}$ & 0.105 & 0.111 & 0.092 \\
$C_{7}$ & 0.099 & 0.112 & 0.091 \\
$C_{8}$ & 0.091 & 0.108 & 0.078 \\
$C_{9}$ & 0.047 & 0.075 & 0.101 \\
$C_{10}$ & 0.072 & 0.074 & 0.108 \\
$C_{11}$ & 0.087 & 0.098 & 0.104 \\
\hline
\end{tabular}

$\operatorname{lev}\left(C_{i}\right)=\left\{l e v^{\text {lower }}\left(C_{i}\right), l e v^{\max }\left(C_{i}\right), l e v^{\text {upper }}\left(C_{i}\right)\right\}$, and the fuzzy risk level of each indicator is shown in Figures 5 and 6.

Referring to the classification definition in Table 6 , lev $v^{\text {upper }}\left(C_{i}\right) \geq 8$ indicates that the upper risk level limit of Company 1's all indicators is above level 8 , which means that these indicators are all IIIrd level risk indicators.

Among them, $l e v^{\max }\left(C_{11}\right)=8$, indicating that indicator $C_{11}$ is a more dangerous privacy risk factor in the process of use, which poses the greatest threat to the privacy security of Company1's mobile services, and it is also a risk factor that users need to pay attention to most in risk management. Except for indicator $C_{11}$, other risk indicators $l e v^{\max }\left(C_{i}\right)<8$, which means they belong to II level risk indicators, indicating that these factors are unlikely to cause privacy risk in the long-term use process.

In addition, $l e v^{\max }\left(C_{6}\right)=2$ indicates that this service has relatively high security in encrypted transmission.

In Figure 6, only $l e v^{\text {upper }}\left(C_{3}\right)<8$, indicating that only the maximum risk level of $C_{3}$ is lower than level III, which means that the services of Company2 have no major privacy risk threat in terms of "mobile advertising attack."

$l e v^{\max }\left(C_{9}\right)=9$ and $l e v^{\max }\left(C_{11}\right)=8$, indicating that these two indicators are dangerous privacy risk factors in the use of company 2's service, and users need to pay more attention 
TABle 9: Assessment distribution results of risk indicator frequency level of Company1.

\begin{tabular}{|c|c|c|c|c|c|c|c|c|c|}
\hline$A$ & $m_{1}\left(A_{1}\right)$ & $m_{2}\left(A_{2}\right)$ & $m_{3}\left(A_{3}\right)$ & $m_{1}\left(A_{1}\right)$ & $m_{2}\left(A_{2}\right)$ & $m_{3}\left(A_{3}\right)$ & $m_{1}\left(A_{1}\right)$ & $m_{2}\left(A_{2}\right)$ & $m_{3}\left(A_{3}\right)$ \\
\hline & & $C_{1}$ & & & $C_{2}$ & & & $C_{3}$ & \\
\hline 1 & 0 & 0 & 0 & 0.1 & 0.1 & 0 & 0 & 0 & 0 \\
\hline $1-2$ & 0.3 & 0.3 & 0.3 & 0.6 & 0.5 & 0.6 & 0 & 0 & 0 \\
\hline 2 & 0.2 & 0.1 & 0.1 & 0.1 & 0.2 & 0.2 & 0 & 0.1 & 0.1 \\
\hline $2-3$ & 0.5 & 0.6 & 0.6 & 0.2 & 0.2 & 0.2 & 0.1 & 0.3 & 0.2 \\
\hline 3 & 0 & 0 & 0 & 0 & 0 & 0 & 0.1 & 0.1 & 0.1 \\
\hline $3-4$ & 0 & 0 & 0 & 0 & 0 & 0 & 0.6 & 0.4 & 0.5 \\
\hline \multirow[t]{2}{*}{4} & 0 & 0 & 0 & 0 & 0 & 0 & 0.2 & 0.1 & 0.1 \\
\hline & & $C_{4}$ & & & $C_{5}$ & & & $C_{6}$ & \\
\hline 1 & 0.8 & 0.8 & 0.8 & 0 & 0 & 0 & 0.3 & 0.3 & 0.4 \\
\hline $1-2$ & 0.2 & 0.1 & 0.1 & 0.1 & 0.1 & 0.1 & 0.3 & 0.3 & 0.3 \\
\hline 2 & 0 & 0.1 & 0.1 & 0.1 & 0.1 & 0.1 & 0.3 & 0.2 & 0.2 \\
\hline $2-3$ & OS & 0 & 0 & 0.6 & 0.5 & 0.4 & 0.1 & 0.2 & 0.1 \\
\hline 3 & 0 & 0 & 0 & 0.2 & 0 & 0.2 & 0 & 0 & 0 \\
\hline $3-4$ & 0 & 0 & 0 & 0 & 0.3 & 0.2 & 0 & 0 & 0 \\
\hline \multirow[t]{2}{*}{4} & 0 & 0 & 0 & 0 & 0 & 0 & 0 & 0 & 0 \\
\hline & & $C_{7}$ & & & $C_{8}$ & & & $C_{9}$ & \\
\hline 1 & 0.1 & 0.1 & 0.1 & 0.1 & 0.1 & 0.1 & 0 & 0 & 0 \\
\hline $1-2$ & 0.2 & 0.2 & 0.2 & 0.5 & 0.6 & 0.3 & 0.5 & 0.3 & 0.2 \\
\hline 2 & 0.3 & 0.2 & 0.3 & 0 & 0 & 0 & 0.1 & 0 & 0 \\
\hline $2-3$ & 0.4 & 0.4 & 0.3 & 0.3 & 0.2 & 0.4 & 0.4 & 0.5 & 0.6 \\
\hline 3 & 0 & 0.1 & 0.1 & 0 & 0 & 0.1 & 0 & 0.1 & 0.1 \\
\hline $3-4$ & 0 & 0 & 0 & 0.1 & 0.1 & 0.1 & 0 & 0.1 & 0.1 \\
\hline \multirow[t]{2}{*}{4} & 0 & 0 & 0 & 0 & 0 & 0 & 0 & 0 & 0 \\
\hline & & $C_{10}$ & & & $C_{11}$ & & & & \\
\hline 1 & 0 & 0 & 0 & 0 & 0 & 0 & & & \\
\hline $1-2$ & 0.3 & 0.3 & 0.2 & 0.4 & 0.1 & 0.2 & & & \\
\hline 2 & 0 & 0 & 0 & 0 & 0.1 & 0.1 & & & \\
\hline $2-3$ & 0.4 & 0.5 & 0.8 & 0.4 & 0.5 & 0.6 & & & \\
\hline 3 & 0.1 & 0 & 0 & 0.1 & 0 & 0 & & & \\
\hline $3-4$ & 0.2 & 0.2 & 0 & 0.1 & 0.3 & 0.1 & & & \\
\hline 4 & 0 & 0 & 0 & 0 & 0 & 0 & & & \\
\hline
\end{tabular}

TABle 10: Assessment distribution results of risk indicator loss level of Company1.

\begin{tabular}{|c|c|c|c|c|c|c|c|c|c|}
\hline & $m_{1}\left(A_{1}\right)$ & $m_{2}\left(A_{2}\right)$ & $m_{3}\left(A_{3}\right)$ & $m_{1}\left(A_{1}\right)$ & $m_{2}\left(A_{2}\right)$ & $m_{3}\left(A_{3}\right)$ & $m_{1}\left(A_{1}\right)$ & $m_{2}\left(A_{2}\right)$ & $m_{3}\left(A_{3}\right)$ \\
\hline & & $C_{1}$ & & & $C_{2}$ & & & $C_{3}$ & \\
\hline 1 & 0 & 0 & 0 & 0 & 0 & 0 & 0.1 & 0.2 & 0.1 \\
\hline $1-2$ & 0 & 0 & 0 & 0.4 & 0.2 & 0.3 & 0.8 & 0.8 & 0.8 \\
\hline 2 & 0 & 0 & 0.1 & 0.1 & 0.2 & 0.1 & 0.1 & 0 & 0.1 \\
\hline $2-3$ & 0.8 & 0.9 & 0.7 & 0.5 & 0.4 & 0.5 & 0 & 0 & 0 \\
\hline 3 & 0 & 0.1 & 0.1 & 0 & 0.1 & 0.1 & 0 & 0 & 0 \\
\hline 3-4 & 0.2 & 0 & 0.1 & 0 & 0.1 & 0 & 0 & 0 & 0 \\
\hline \multirow[t]{2}{*}{4} & 0 & 0 & 0 & 0 & 0 & 0 & 0 & 0 & 0 \\
\hline & & $C_{4}$ & & & $C_{5}$ & & & $C_{6}$ & \\
\hline 1 & 0 & 0 & 0 & 0 & 0 & 0 & 0.1 & 0.3 & 0.2 \\
\hline $1-2$ & 0 & 0 & 0 & 0.2 & 0.3 & 0.1 & 0.7 & 0.6 & 0.5 \\
\hline 2 & 0 & 0 & 0 & 0.1 & 0.1 & 0.1 & 0.1 & 0 & 0 \\
\hline $2-3$ & 0.2 & 0.2 & 0.4 & 0.6 & 0.5 & 0.5 & 0.1 & 0.1 & 0.2 \\
\hline 3 & 0.2 & 0.2 & 0.2 & 0 & 0 & 0.2 & 0 & 0 & 0 \\
\hline $3-4$ & 0.5 & 0.5 & 0.3 & 0.1 & 0.1 & 0.1 & 0 & 0 & 0.1 \\
\hline \multirow[t]{2}{*}{4} & 0.1 & 0.1 & 0.1 & 0 & 0 & 0 & 0 & 0 & 0 \\
\hline & & $C_{7}$ & & & $C_{8}$ & & & $C_{9}$ & \\
\hline 1 & 0.3 & 0.1 & 0.1 & 0.3 & 0.1 & 0 & 0 & 0 & 0 \\
\hline $1-2$ & 0.5 & 0.6 & 0.2 & 0.5 & 0.2 & 0.4 & 0 & 0 & 0.1 \\
\hline
\end{tabular}


Table 10: Continued.

\begin{tabular}{|c|c|c|c|c|c|c|c|c|c|}
\hline & $m_{1}\left(A_{1}\right)$ & $m_{2}\left(A_{2}\right)$ & $m_{3}\left(A_{3}\right)$ & $m_{1}\left(A_{1}\right)$ & $m_{2}\left(A_{2}\right)$ & $m_{3}\left(A_{3}\right)$ & $m_{1}\left(A_{1}\right)$ & $m_{2}\left(A_{2}\right)$ & $m_{3}\left(A_{3}\right)$ \\
\hline 2 & 0 & 0.1 & 0.3 & 0 & 0.1 & 0.1 & 0 & 0 & 0 \\
\hline $2-3$ & 0.2 & 0.2 & 0.3 & 0.2 & 0.5 & 0.5 & 0.6 & 0.7 & 0.5 \\
\hline 3 & 0 & 0 & 0.1 & 0 & 0.1 & 0 & 0.1 & 0.1 & 0 \\
\hline $3-4$ & 0 & 0 & 0 & 0 & 0 & 0 & 0.2 & 0.2 & 0.4 \\
\hline \multirow[t]{2}{*}{4} & 0 & 0 & 0 & 0 & 0 & 0 & 0.1 & 0 & 0 \\
\hline & & $C_{10}$ & & & $C_{11}$ & & & & \\
\hline 1 & 0 & 0 & 0 & 0 & 0 & 0 & & & \\
\hline $1-2$ & 0.4 & 0.5 & 0.6 & 0 & 0 & 0 & & & \\
\hline 2 & 0 & 0 & 0.1 & 0 & 0 & 0 & & & \\
\hline $2-3$ & 0.5 & 0.5 & 0.3 & 0.2 & 0.2 & 0.2 & & & \\
\hline 3 & 0 & 0 & 0 & 0 & 0 & 0 & & & \\
\hline $3-4$ & 0.1 & 0 & 0 & 0.4 & 0.4 & 0.3 & & & \\
\hline 4 & 0 & 0 & 0 & 0.4 & 0.4 & 0.5 & & & \\
\hline
\end{tabular}

TABLE 11: Risk indicator frequency level of Company 1 after fusion.

\begin{tabular}{|c|c|c|c|c|c|c|}
\hline$\underline{\underline{A}}$ & & & & & & \\
\hline & $C_{1}$ & $C_{2}$ & $C_{3}$ & $C_{4}$ & $C_{5}$ & $C_{6}$ \\
\hline 1 & 0.0224 & 0.2355 & 0.0000 & 0.9902 & 0.0012 & 0.4599 \\
\hline 2 & 0.8285 & 0.7570 & 0.0157 & 0.0098 & 0.3958 & 0.5365 \\
\hline 3 & 0.1491 & 0.0075 & 0.6702 & 0.0000 & 0.6031 & 0.0036 \\
\hline 4 & 0.0000 & 0.0000 & 0.3141 & 0.0000 & 0.0000 & 0.0000 \\
\hline & $C_{7}$ & $C_{8}$ & $C_{9}$ & $C_{10}$ & $C_{11}$ & \\
\hline 1 & 0.0395 & 0.2438 & 0.0336 & 0.0186 & 0.0094 & \\
\hline 2 & 0.8433 & 0.6502 & 0.7159 & 0.5773 & 0.5922 & \\
\hline 3 & 0.1171 & 0.1045 & 0.2506 & 0.4041 & 0.3948 & \\
\hline 4 & 0.0000 & 0.0015 & 0.0000 & 0.0000 & 0.0035 & \\
\hline
\end{tabular}

TABLE 12: Risk indicator loss level of Company1 after fusion.

\begin{tabular}{|c|c|c|c|c|c|c|}
\hline$\underline{A}$ & & & & & & \\
\hline & $C_{1}$ & $C_{2}$ & $C_{3}$ & $C_{4}$ & $C_{5}$ & $C_{6}$ \\
\hline 1 & 0.0000 & 0.0260 & 0.5556 & 0.0000 & 0.0066 & 0.5316 \\
\hline 2 & 0.3902 & 0.7792 & 0.4444 & 0.0180 & 0.6231 & 0.4652 \\
\hline 3 & 0.6098 & 0.1948 & 0.0000 & 0.8200 & 0.3692 & 0.0032 \\
\hline 4 & 0.0000 & 0.0000 & 0.0000 & 0.1620 & 0.0011 & 0.0000 \\
\hline & $C_{7}$ & $C_{8}$ & $C_{9}$ & $C_{10}$ & $C_{11}$ & \\
\hline 1 & 0.2442 & 0.1341 & 0.0000 & 0.1081 & 0.0000 & \\
\hline 2 & 0.7326 & 0.7821 & 0.2320 & 0.8108 & 0.0114 & \\
\hline 3 & 0.0233 & 0.0838 & 0.7459 & 0.0811 & 0.2571 & \\
\hline 4 & 0.0000 & 0.0000 & 0.0221 & 0.0000 & 0.7314 & \\
\hline
\end{tabular}

to these two risk factors in the use process. Combining the meanings of $C_{9}$ and $C_{11}$, it shows that users need to strengthen the security in "permission operation" and "key management" when using this financial service.

In addition, $l e v^{\max }\left(C_{3}\right)=l e v^{\max }\left(C_{10}\right)=2$, indicating that this service has high security in terms of "mobile advertising attack" and "third-party application attack."

(2) Risk Level Comparison in the 2nd Layer. Similarly, if the risk level of each risk class in layer 2 is expressed as $\operatorname{lev}\left(\beta_{j}\right)=\left\{\operatorname{le} v^{\text {lower }}\left(\beta_{j}\right), \operatorname{lev}^{\max }\left(\beta_{j}\right)\right.$, lev $\left.^{\text {upper }}\left(\beta_{j}\right)\right\}$, the fuzzy risk level of each risk class is shown in Figure 7.

As shown in Figure 7, there is little difference in the privacy risk levels of the two mobile services in different risk categories. lev $v^{\max }\left(\beta_{j}\right)<5$ means that all risk categories of the two companies belong to II level risk category, which means that the mobile services of the two companies are in a relatively safe state in most cases. In comparison, the lowest level of Company 2's all risk categories, $l e v^{\max }\left(\beta_{j}\right)>2$, indicating that the privacy risk of Company 2 is relatively high.

(3) Risk Level Comparison in the 1st Layer. Similarly, if the risk level of the entire service is expressed as $l e v=\left\{l e v^{\text {lower }}, l e v^{\max }, l e v^{\text {upper }}\right\}$, the fuzzy risk level of the entire mobile services of the two companies is shown in Table 13.

As shown in Table 13, the subordinate range of Company 1 's privacy risk level is $[1.469,10.476]$, while the subordinate 


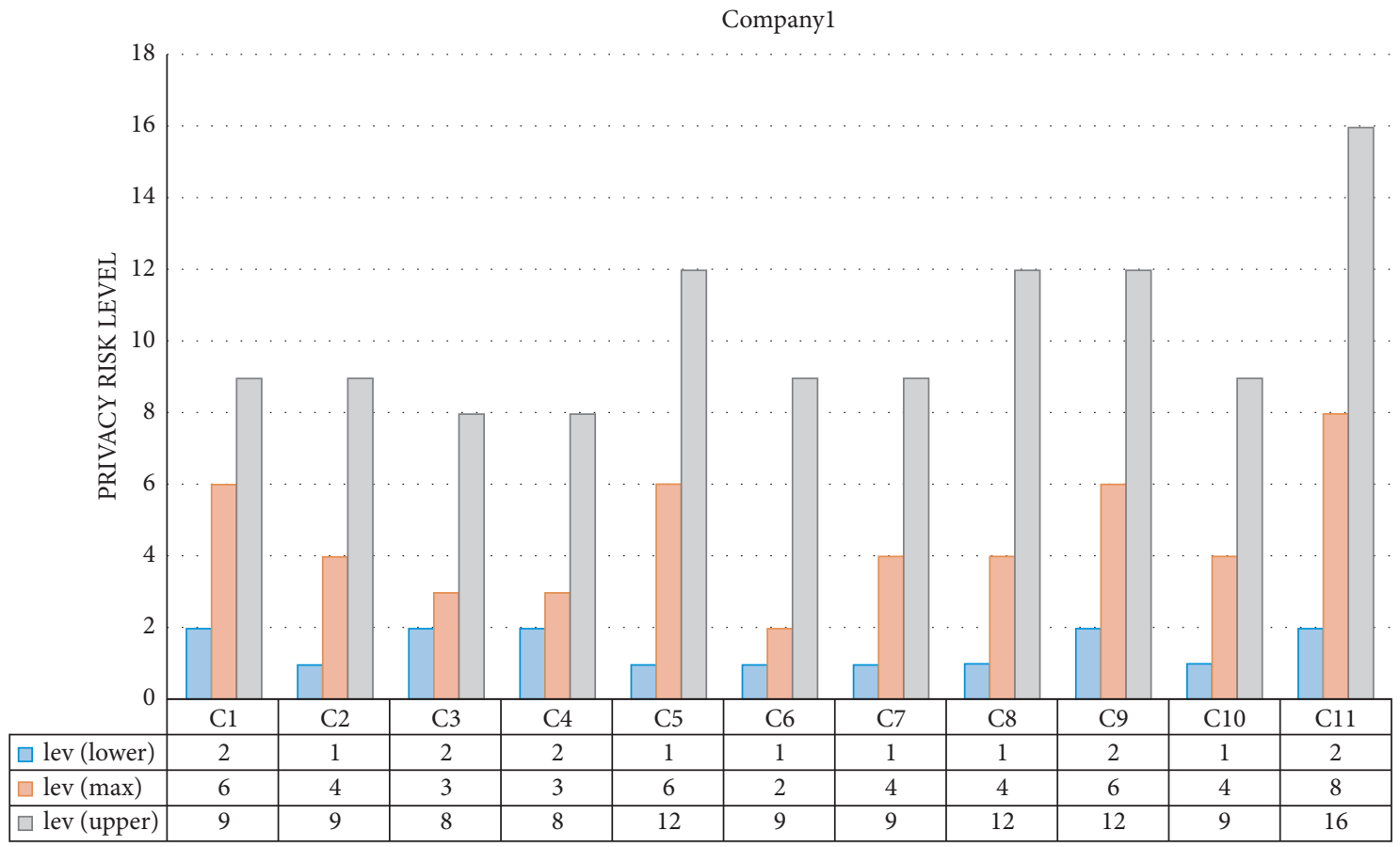

Figure 5: Privacy risk level of each indicator of Company 1's mobile service.

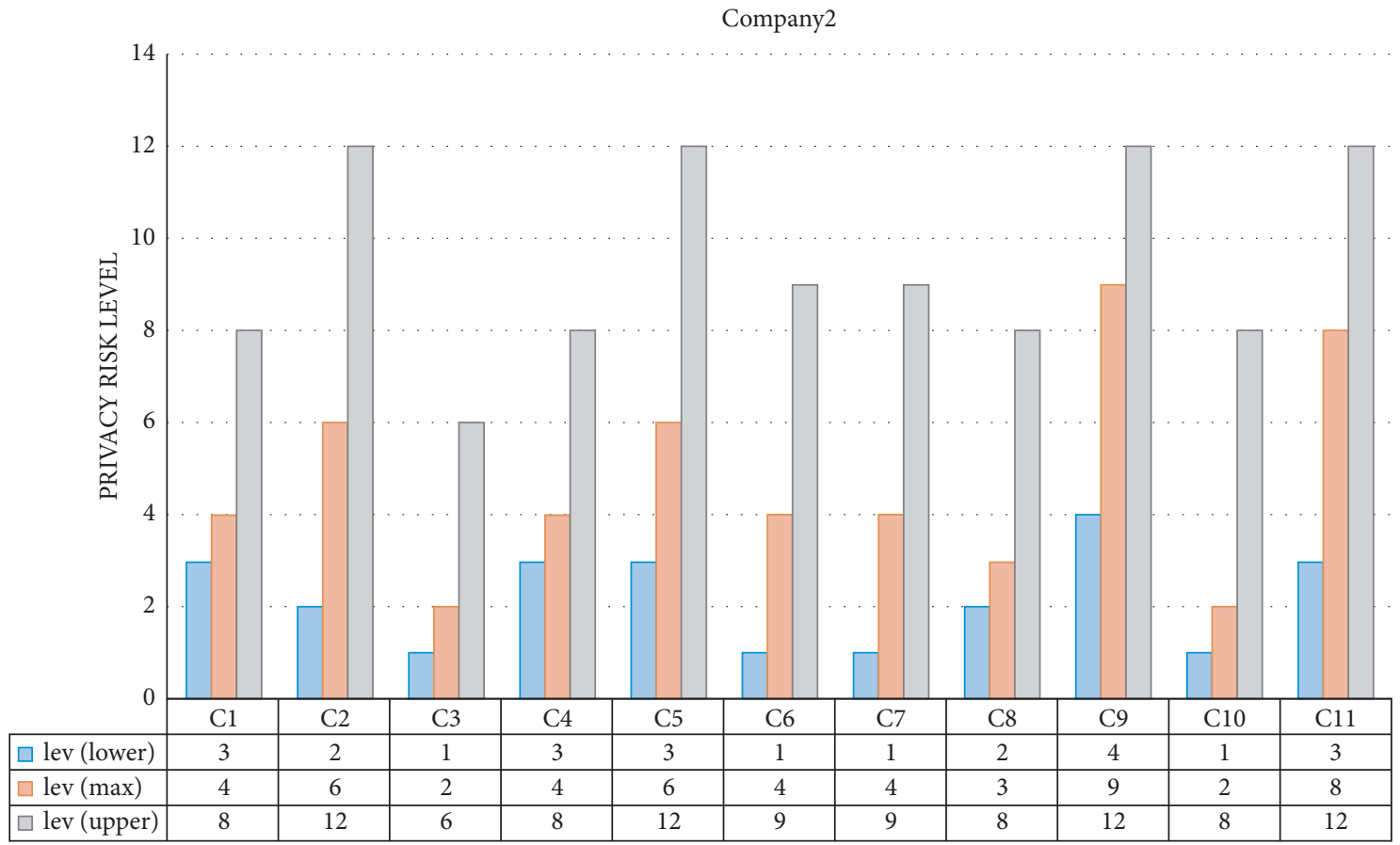

Figure 6: Privacy risk level of each indicator of Company2's mobile service. 

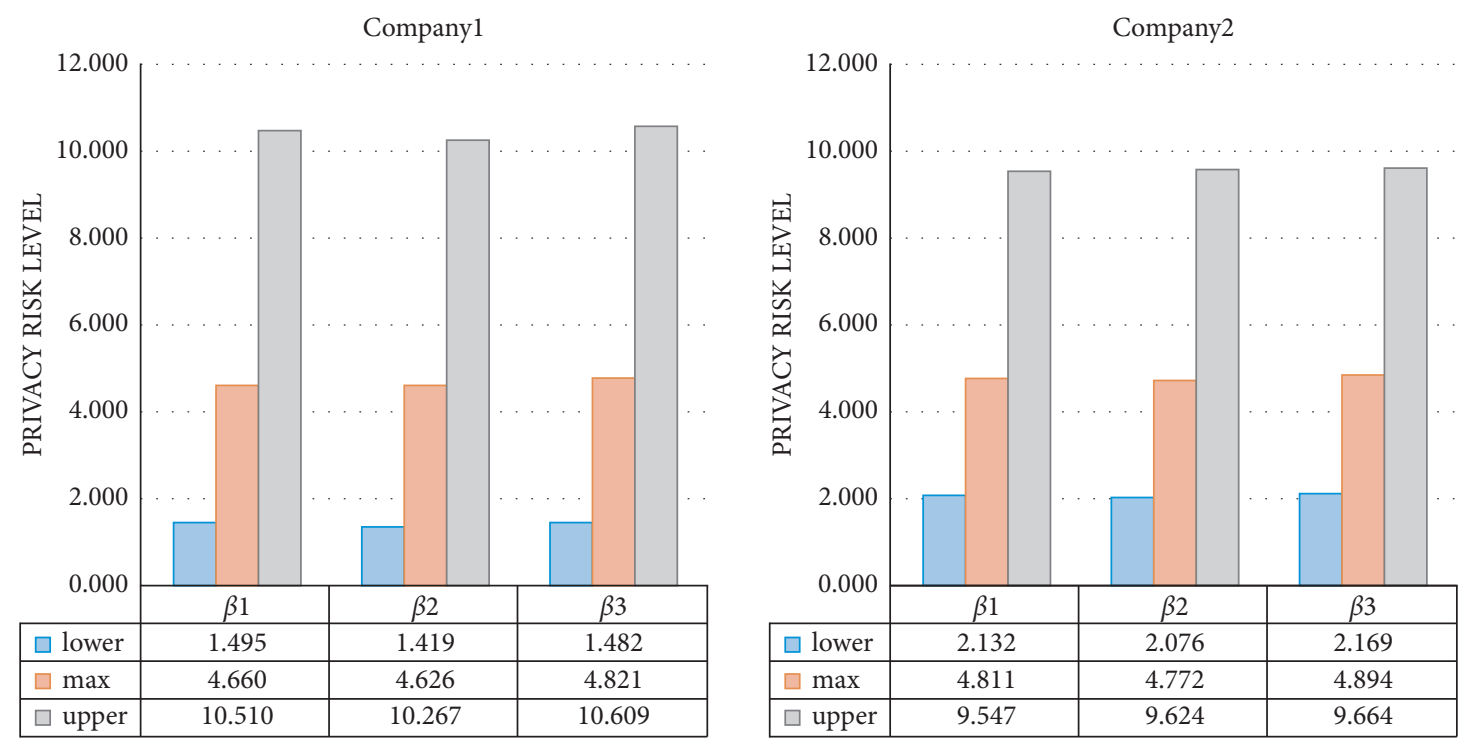

Figure 7: Privacy risk levels of each risk category of the two companies.

range of Company 2's privacy risk level is [2.129, 9.609]. Among them, the subordinate range of Company 1's privacy risk level is relatively large, indicating that the fluctuation range of Company 1's privacy risk level is relatively large. However, on the whole, the two services' privacy risk level $l e v^{\max }<5$, indicating that the two services are at a relatively safe risk level in the long-term use process.

From the above case analysis, it can be seen that the method proposed in this paper is effective and feasible and can provide users with detailed and comprehensive risk assessment results. Based on these assessment results, users can conduct risk analysis from different angles according to their own needs, so as to reasonably manage their own privacy information.

6.2. Method Comparison. In order to illustrate the effectiveness and characteristics of the methods proposed in this paper, we carry out the following discussion and comparison.

The methods proposed in this paper are mainly used to assess the privacy security of mobile services. Compared with trust computing, they are also a method for security assessment and analysis. During the assessment, for the purpose of security assessment, the two methods all need to sort out the measurement indicators affecting system security and their related attributes and then adopt corresponding methods to assess these indicators. These corresponding methods include AHP [36-38], information entropy [39-41], and trust chain [42-44]. In these methods, trust chain is a method which is mainly used to detect whether the system is attacked or damaged. This method can effectively protect the security of the system. However, this method mainly assesses the vulnerabilities in software and hardware and does not assess other factors such as management risk, man-made operation risk, and application environment risk. In addition, using this method requires the establishment of a special trust chain, and the cost of assessment is high.

Therefore, as a risk assessment method, in order to illustrate the characteristics of the method proposed in this paper, it should be compared with other common risk assessment methods, such as risk assessment method based on AHP [45-47], risk assessment method based on risk matrix $[48,49]$, and risk assessment method based on information entropy [26, 49-52]. They are all mature risk assessment methods, which have been widely used and can provide users with effective risk assessment results.

This paper compares the proposed method with the above methods around the following aspects.

(i) Cost: it refers to the cost required for assessment, including the difficulty of expert assessment, task quantity, and computational complexity. The higher the cost, the greater the calculation cost.

(ii) Objectivity: it refers to whether the assessment results can objectively reflect the privacy risk of mobile services. The higher the objectivity, the more accurate the assessment results can describe the privacy risk of the service.

(iii) Completeness: it refers to the comprehensiveness of the privacy risk assessment results. The more 
TABLE 13: Privacy risk level comparison of the entire mobile services between the two companies.

\begin{tabular}{|c|c|c|c|c|c|c|c|}
\hline \multicolumn{4}{|c|}{ Company1 } & \multicolumn{4}{|c|}{ Company2 } \\
\hline & $l e v^{\text {lower }}$ & $l e v^{\max }$ & $l e v^{\text {upper }}$ & & $l e v^{\text {lower }}$ & $l e v^{\max }$ & $l e v^{\text {upper }}$ \\
\hline & 1.469 & 4.706 & 10.476 & & 2.129 & 4.829 & 9.609 \\
\hline \multicolumn{4}{|c|}{ Frequency level of each risk category } & \multicolumn{4}{|c|}{ Frequency level of each risk category } \\
\hline$f^{\text {lower }}$ & $\begin{array}{c}\beta_{1} \\
1.112\end{array}$ & $\begin{array}{c}\beta_{2} \\
1.089\end{array}$ & $\begin{array}{c}\beta_{3} \\
1.100\end{array}$ & $f^{\text {lower }}$ & $\begin{array}{c}\beta_{1} \\
1.072\end{array}$ & $\begin{array}{c}\beta_{2} \\
1.074\end{array}$ & $\begin{array}{c}\beta_{3} \\
1.108\end{array}$ \\
\hline$f^{\max }$ & 2.115 & 2.125 & 2.132 & $f^{\max }$ & 1.736 & 1.746 & 1.770 \\
\hline$f^{\text {upper }}$ & 3.247 & 3.163 & 3.247 & $f^{\text {upper }}$ & 2.662 & 2.672 & 2.662 \\
\hline \multicolumn{4}{|c|}{ Loss level of each risk class } & \multicolumn{4}{|c|}{ Loss level of each risk class } \\
\hline$l^{\text {lower }}$ & $\begin{array}{c}\beta_{1} \\
1.344\end{array}$ & $\begin{array}{c}\beta_{2} \\
1.303\end{array}$ & $\begin{array}{c}\beta_{3} \\
1.347\end{array}$ & $l^{\text {lower }}$ & $\begin{array}{c}\beta_{1} \\
1.988\end{array}$ & $\begin{array}{c}\beta_{2} \\
1.933\end{array}$ & $\begin{array}{c}\beta_{3} \\
1.957\end{array}$ \\
\hline$l^{\max }$ & 2.203 & 2.176 & 2.262 & $l^{\max }$ & 2.771 & 2.732 & 2.764 \\
\hline$l^{\text {upper }}$ & 3.237 & 3.246 & 3.268 & $l^{\text {upper }}$ & 3.586 & 3.601 & 3.630 \\
\hline
\end{tabular}

TABLE 14: Comparison between this paper's method and other methods in different aspects.

\begin{tabular}{|c|c|c|}
\hline Method & The cost required for assessment & Methods to improve objectivity \\
\hline AHP & Times of establishing judgment matrix $\gg 4$ & Pairwise comparison method of weight \\
\hline This paper & $\begin{array}{l}\text { Times of establishing judgment matrix }=4 \text {; need to assess the risk level of } \\
\qquad 11 \text { risk indicators }\end{array}$ & $\begin{array}{c}\text { Pairwise comparison method of weight; } \\
\text { Fusion method of expert results based on } \\
\text { D-S; } \\
\text { Risk level description based on fuzzy } \\
\text { theory. }\end{array}$ \\
\hline Risk matrix & Need to assess the risk level of 11 risk indicators & $\begin{array}{l}\text { Only uses a fixed value to describe the risk } \\
\text { level }\end{array}$ \\
\hline $\begin{array}{l}\text { Information } \\
\text { entropy }\end{array}$ & $\begin{array}{l}\text { Need to measure the uncertainty of } 11 \text { risk indicators and calculate their } \\
\text { entropy weight }\end{array}$ & Entropy weight method \\
\hline AHP & $\begin{array}{l}\text { Comprehensiveness of the assessment } \\
\text { Analysis with } 3 \text { categories and } 3 \text { layers }\end{array}$ & $\begin{array}{c}\text { Available assessment results } \\
\text { Risk weight }\end{array}$ \\
\hline This paper & Risk frequency and risk loss analysis from 3 categories and 3 layers & $\begin{array}{l}\text { Risk weight, risk frequency level, and risk } \\
\text { loss level }\end{array}$ \\
\hline \multirow{2}{*}{$\begin{array}{l}\text { Risk matrix } \\
\text { Information } \\
\text { entropy }\end{array}$} & Risk frequency and risk loss analysis & Risk frequency level and risk loss level \\
\hline & Uncertainty analysis and entropy weight analysis of risk & Risk weight and risk uncertainty \\
\hline
\end{tabular}

privacy risk assessment results this method can provide to users, the more comprehensive the method is.

(iv) Decision support: it refers to whether the assessment results can effectively help users manage privacy information reasonably. The higher the reference value of the assessment results, the higher the decision support.

(v) Difficulty of data acquisition: it refers to the difficulty of obtaining input data.

(vi) Scalability: it refers to the scalability of this method when dealing with new problems.

(vii) Time complexity and space complexity: it refers to the time complexity and space complexity required by this method.

As shown in Table 14, this paper first compares the methods around the four aspects of cost, objectivity, completeness, and decision support.

\subsubsection{Cost Comparison}

(1) AHP: the judgment matrix established in the assessment process of this method is not completely consistent. In order to meet the requirements of consistency, the judgment matrix usually needs to be adjusted many times.

(2) This paper's method: like AHP, this method needs to establish a special judgment matrix in the assessment process. But when establishing the judgment matrix, this paper proposes to use fuzzy consistency matrix to ensure the consistency of assessment results, which can effectively reduce the difficulty of expert assessment.

(3) Risk matrix: it is only necessary to make a simple level assessment on each risk factor from risk occurrence frequency and risk loss, and its calculation process is very simple.

(4) Information entropy: this method needs to establish a special model and calculate it in combination with the 


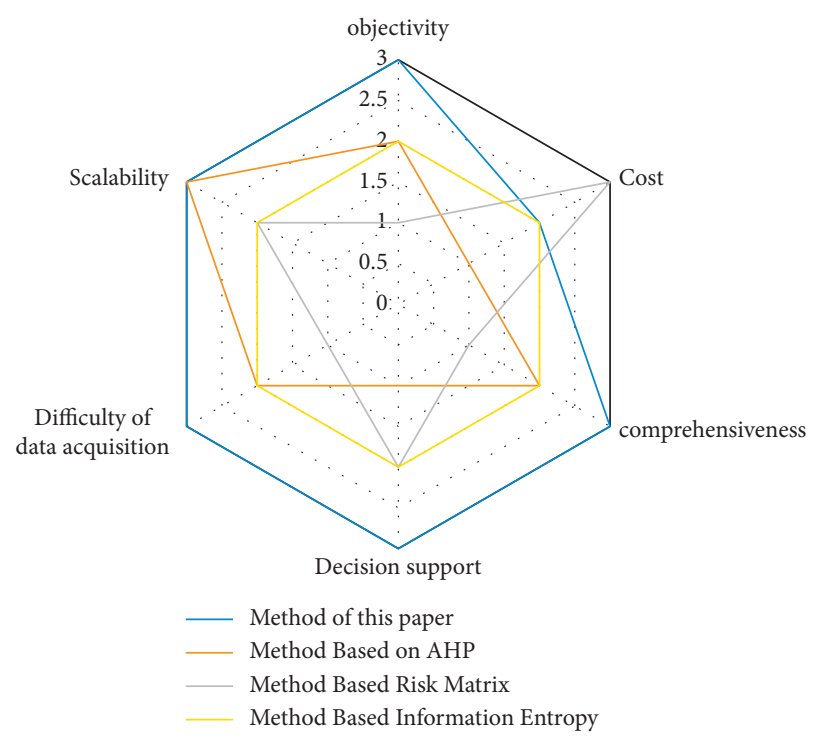

FIgURE 8: Comparison of characteristics between this method and other methods.

information entropy formula, but it does not need to calculate multiple times like the FAHP method.

\subsubsection{Objectivity Comparison}

(1) AHP: the method of pairwise comparison is adopted in the assessment process, which reduces the impact of human subjective preference on the assessment results. Its assessment results are relatively objective.

(2) This paper method: in the process of weight assessment, this method inherits the advantages of AHP pairwise comparison method. In the subsequent risk level assessment process, this method combines D-S theory to solve the conflict between experts and combines fuzzy theory to describe the level of privacy risk objectively.

(3) Risk matrix: this method only uses a fixed value to describe the risk level, which is too subjective to reflect the real risk level.

(4) Information entropy: this method effectively describes the risk from the perspective of uncertainty, but it cannot effectively solve the problem of "conflict information" in the assessment process. The assessment results are relatively objective.

\subsubsection{Comprehensiveness Comparison}

(1) AHP: this method can provide users with multidimensional and multilevel risk assessment results based on the risk attribute model

(2) This paper's method: this method can also provide users with multidimensional and multilevel risk assessment results and can provide users with the risk level assessment results of risk frequency and risk loss

(3) Risk matrix: this method can only assess each risk factor independently
(4) Information entropy: this method establishes a special risk assessment system, which can also provide users with multilevel assessment results

\subsubsection{Comparison on the Degree of Decision Support}

(1) AHP: this method can only calculate the impact weight of each risk factor relative to privacy security, but it lacks the measurement of the level of risk.

(2) This paper's method: it assesses the privacy risk from two aspects-risk frequency and risk loss-and defines the fuzzy triangle number of privacy risk level, including the maximum trust risk level, the maximum risk level, and the minimum risk level. Users can clearly understand each risk and the impact of different risk categories.

(3) Risk matrix: this method can provide users with the assessment results of risk occurrence frequency and risk loss and help users understand the differences of various factors from the above two aspects.

(4) Information entropy: this method describes the level of risk through the degree of uncertainty, which can provide users with the ranking of relevant risk factors, but it does not describe risk frequency and risk loss in detail.

\subsubsection{Comparison on Difficulty of Data Acquisition}

(1) AHP: it is necessary to obtain the relative weight of each risk indicator and the relative weight of each risk category

(2) This paper's method: it is necessary to obtain the relative weight of each risk indicator, the relative weight of each risk category, the risk frequency level and risk loss level of each indicator

(3) Risk matrix: it is necessary to obtain the risk frequency level and risk loss level of each indicator 
TABLe 15: Time complexity and space complexity of each method.

\begin{tabular}{lccr}
\hline Method & & $T(n)$ & $S(n)$ \\
\hline Method of this paper & Average case & Best case & Worst case \\
Method based on AHP & $O\left(n^{2}\right)$ & $O\left(n^{2}\right)$ & $O\left(n^{2}\right)$ \\
Method-based risk matrix & $O\left(n^{2} \log n\right)$ & $O\left(n^{2}\right)$ & $O\left(n^{2} \log n\right)$ \\
Method-based information entropy & $O(1)$ & $O(1)$ & $O(\log n)$ \\
\hline
\end{tabular}

(4) Information entropy: it needs to sort out the uncertain factors affecting each risk indicator or risk category

6.2.6. Comparison on Scalability. Taking the service evaluated in this paper as a reference. When it is necessary to carry out more security assessment about this service from more aspects, the scalability comparison of each method is as follows:

(1) AHP: using this method, new risk classes and risk indicators need to be added to the established risk attribute model, which will not affect the risk assessment method.

(2) This paper's method: like the AHP method, only the risk attribute model needs to be extended

(3) Risk matrix: using this method, although the corresponding risk indicators can be added, it cannot meet the new needs of security assessment

(4) Information entropy: using this method, with the increase of risk indicators, the uncertainty of the whole service will be greatly affected, and its assessment model will also be greatly affected and even need to be reestablished

The above discussion shows that when there are new risk problems or new safety assessment requirements, AHP method and this paper method have good expansibility. In contrast, the method-based information entropy and the method based risk matrix have poor scalability.

To sum up, use $\{\operatorname{High}=3$, Medium $=2$, Low $=1\}$ to describe the characteristics of the above methods, respectively, and the comparison results is shown in Figure 8.

In Figure 8, the value 3 indicates that the method has a higher score than other methods in some respects. The value 2 indicates that the method has a moderate score in some respects, and the value 1 indicates that the method has the lowest score in some respects.

6.2.7. Comparison on Time Complexity and Space Complexity. In addition to the comparison of the above 6 aspects, this paper also carries out the comparative analysis of time complexity and space complexity. Suppose the privacy security of a mobile service is affected by $n$ risk indicators. Taking this mobile service as the assessment object, the time complexity and space complexity of each method are shown in Table 15.
(1) This paper: the method proposed in this paper needs $n(n-1) / 2$ weight judgments and $2 n$ risk level assessments. The total spaces for storing risk frequency level, risk loss level and risk level are $3 n$, and the space for storing risk assessment weight is $n$.

(2) AHP: using the AHP method, in the best case, only $n(n-1) / 2$ weight judgments are required. However, in order to pass the consistency test, it is almost necessary to expand $n(n-1) * \log n / 2$ weight judgments. The required storage space is the same as the method in this paper.

(3) Risk matrix: both in the average and best cases, we only need to set $n$ parameters and conduct 1 assessment for the risk frequency level and risk loss level of $n$ indicators. When there is a conflict between expert assessments, it is necessary to reevaluate the risk level continuously. At this time, the time complexity is $\log n$. In terms of spatial complexity, 3 $n$ spaces are required to store risk frequency level, risk loss level, and risk level.

(4) Information entropy: using this method requires $n$ assessments for the uncertainty of $n$ indicators. $n$ spaces are required to store the uncertainty level of each indicator.

In general, this paper introduces FAHP and D-S theory into mobile service privacy risk assessment and proposes a comprehensive assessment method combining risk weight and risk level. This method proposed in this paper inherits the advantages of AHP method and has good scalability. Based on the AHP hierarchical model, this paper uses the fuzzy consistency matrix to solve the consistency problem of judgment matrix in AHP and improves the efficiency of the method. Through comprehensive assessment of risk weight and risk level, the proposed method improves the objectivity, the degree of decision support, and comprehensiveness about the assessment results. However, in order to improve the comprehensiveness of the assessment results, the method proposed in this paper will also increase the difficulty of obtaining the input data, and its time complexity and space complexity will increase accordingly.

\section{Conclusion}

Firstly, this paper establishes the privacy risk attribute model based on FAHP, uses the fuzzy consistency matrix method to effectively solve the consistency problem of judgment matrix in AHP, and puts forward an effective risk weight assessment method for mobile service privacy risk. Secondly, this paper 
redefines the level of privacy risk combined with fuzzy theory, integrates the expert assessment results combined with D-S theory, effectively solves the "opinion conflict problem" in multiexpert assessment, and realizes the measurement of the privacy risk level of mobile services. Finally, through a series of research, this paper proposes a complete assessment method of mobile service privacy risk based on FAHP and D-S theory. This method is objective and feasible. It can provide users with privacy risk assessment results of different dimensions and layers and help users reasonably manage their privacy information. It has long-term significance for the research of mobile service privacy security. In the future research, to provide users with more accurate and detailed assessment results, it is also necessary to further give the corresponding trust degree of risk level based on the research results, and explore effective risk dynamic assessment methods.

\section{Data Availability}

The data used to support the findings of this study are available from the corresponding author upon request.

\section{Ethical Approval}

This article does not contain any studies with human participants or animals performed by any of the authors.

\section{Conflicts of Interest}

The authors declare that they have no conflicts of interest.

\section{Authors' Contributions}

All authors contributed to the study conception and design. Material preparation, data collection, and analysis were performed by Tilei Gao, Rong Jiang, Li Jia, and Di Yang. The first draft of the manuscript was written by Ming Yang, and all authors commented on previous versions of the manuscript. All authors read and approved the final manuscript.

\section{Acknowledgments}

This research was supported by the National Natural Science Foundation of China (no. 11861071), Yunnan Fundamental Research Projects (nos. 202101AT070211, 202101AT070415, and 202101AT070464), and the Scientific Research Foundation of Yunnan Education Department (no. 2022J0475).

\section{References}

[1] Newzoo, Global Mobile Market Report, 2021, China.

[2] L. Hua, China Mobile Internet Development Report, People Daily, China, 2021.

[3] China Telecom cloud Network Security Technology Co Ltd, Annual Observation Report on Internet Mobile Application Privacy in China, China Telecom cloud Network Security Technology Co Ltd, China, 2020.

[4] L.-E. Wang, Y.-X. Xu, X.-X. Li, and P. Liu, "P2P-based privacy protection strategy in mobile-commerce recommender system," Computer Science, vol. 44, no. 9, pp. 184-189, 2017.
[5] R.-x. Li, X.-h. Dong, X.-w. Gu, W.-w. Zhou, and C. Wang, "Overview of the data security and privacy-preserving of mobile cloud services," Journal on Communications, vol. 34, no. 12 , p. 9, 2013.

[6] D. Naga, A. Dhavalya, V. D. Sai, and K. Srikanth, "A detailed study on risk assessment of mobile app permissions," International Journal of Engineering \& Technology, vol. 7, no. 1, p. 297, 2017.

[7] X. Liu, S. Zhu, W. Wang, and J. Liu, "Alde: privacy risk analysis of analytics libraries in the android ecosystem," in Proceedings of the International Conference on Security and Privacy in Communication Systems, Guangzhou, China, October 2016.

[8] G. Shrivastava and P. Kumar, "Intent and permission modeling for privacy leakage detection in android," Energy Systems, pp. 1-14, 2019.

[9] N. W. Lo, K. H. Yeh, and C. Y. Fan, "Leakage detection and risk assessment on privacy for android applications: LRPdroid," IEEE Systems Journal, vol. 10, no. 4, pp. 1-9, 2016.

[10] A. S. Yüksel, M. E. Yüksel, A. Sertbaş, and A. H. Zaim, "Implementation of a web-based service for mobile application risk assessment," Turkish Journal of Electrical Engineering \& Computer Sciences, vol. 25, no. 2, pp. 976-994, 2017.

[11] T. Dehling, F. Gao, S. Schneider, and A. Sunyaev, "Exploring the far side of mobile health: information security and privacy of mobile health apps on iOS and android," JMIR mhealth and uhealth, vol. 3, no. 1, p. e8, 2015.

[12] K. C. Chang, R. N. Zaeem, and K. S. Barber, "A framework for estimating privacy risk scores of mobile apps," Information Security, 2020.

[13] R. Belani and A. Higbee, "Methods and systems for rating privacy risk of applications for smart phones and other mobile platforms. US," 2015.

[14] S. J. De and A. Imine, "Privacy risk analysis of online social networks," Synthesis Lectures on Information Security, Privacy, and Trust, vol. 10, no. 1, pp. 1-109, 2020.

[15] F. Shirazi and A. Iqbal, "Community clouds within M-commerce: a privacy by design perspective," Journal of Cloud Computing: Advances, Systems and Applications, vol. 6, no. 1, 2017.

[16] Y. Ashibani and Q. H. Mahmoud, "Cyber physical systems security: analysis, challenges and solutions," Computers \& Security, vol. 68, pp. 81-97, 2017.

[17] A. Gutierrez, S. O'Leary, N. P. Rana, Y. K. Dwivedi, and T. Calle, "Using privacy calculus theory to explore entrepreneurial directions in mobile location-based advertising: identifying intrusiveness as the critical risk factor," Computers in Human Behavior, vol. 95, 2018.

[18] J. Lee, S. Kim, and W. Kim, “The effects of consumers' perceived privacy control on perceived privacy risk in location-based services," International Journal of Contents, vol. 13, 2017.

[19] K. Schyff, S. Flowerday, and S. Furnell, "Privacy risk and the use of facebook apps: a gender-focused vulnerability assessment," Computers \& Security, vol. 96, Article ID 101866, 2020.

[20] G. Bal, R. Kai, and J. I. Hong, "Styx: privacy risk communication for the android smartphone platform based on apps' data-access behavior patterns," Computers \& Security, vol. 53, pp. 187-202, 2015.

[21] K. Yang, K. Zhang, J. Ren, and X. Shen, "Security and privacy in mobile crowdsourcing networks: challenges and opportunities," IEEE Communications Magazine, vol. 53, no. 8, pp. 75-81, 2015.

[22] N. Laleh, B. Carminati, and E. Ferrari, "Risk assessment in social networks based on user anomalous behaviors," IEEE 
Transactions on Dependable and Secure Computing, vol. 15, no. 2, pp. 295-308, 2018.

[23] S. J. De and D. L. Métayer, "Privacy risk analysis," Synthesis Lectures on Information Security, Privacy, and Trust, vol. 81, no. 3, pp. 1-133, 2016.

[24] M. Xiang, "Research on the risk evaluation of consumers' privacy information disclosure in mobile commerce," Library and Information Service, 2018.

[25] M. Shi, R. Jiang, W. Zhou, S. Liu, and S. Sciancalepore, "A privacy risk assessment model for medical big data based on adaptive neuro-fuzzy theory," Security and Communication Networks, vol. 2020, no. 9, pp. 1-18, 2020.

[26] T. Zhang, K. Zhao, M. Yang, T. Gao, and W. Xie, "Research on privacy security risk assessment method of mobile commerce based on information entropy and Markov," Wireless Communications and Mobile Computing, vol. 2020, Article ID 8888296, 11 pages, 2020.

[27] M. Yang, "Research on privacy security steady StateEvaluation model of mobile application based on information entropy and Markov theory," International Journal on Network Security, vol. 23, no. 5, pp. 807-816, 2021.

[28] A. Ali-Eldin, A. Zuiderwijk, and M. Janssen, "A privacy risk assessment model for open data," Business Modeling and Software Design, 2018.

[29] E. Cayirci, "A risk assessment model for selecting cloud service providers," Journal of Cloud Computing: Advances, Systems and Applications, vol. 5, no. 1, 2016.

[30] F. Meng and X. Chen, "A new method for triangular fuzzy compare wise judgment matrix process based on consistency analysis," International Journal of Fuzzy Systems, vol. 19, no. 1, pp. 27-46, 2017.

[31] X. Zhou, Y. Hu, Y. Deng, F. T. S. Chan, and A. Ishizaka, "A DEMATEL-based completion method for incomplete pairwise comparison matrix in AHP," Annals of Operations Research, vol. 271, no. 2, pp. 1045-1066, 2018.

[32] P. Dutta and Palash, "Uncertainty modeling in risk assessment based on dempster-shafer theory of evidence with generalized fuzzy focal elements," Fuzzy Information and Engineering, vol. 7, no. 1, pp. 15-30, 2015.

[33] Y. Tang, D. Wu, and Z. Liu, “A new approach for generation of generalized basic probability assignment in the evidence theory," Pattern Analysis \& Applications, vol. 24, no. 3, pp. 1007-1023, 2021.

[34] H. Robbins, An Empirical Bayes Approach to Statistics, University of California Press, Berkeley, CA, USA, 2020.

[35] M. Voskoglou, "Use of the triangular fuzzy numbers for student assessment," Computer Science, vol. 3, no. 4, pp. 146-150, 2015.

[36] T. Gao, "A research about trustworthiness metric method of SaaS services based on AHP," in International Conference on Cloud Computing and SecuritySpringer, Berlin, Germany, 2018.

[37] X. Deng and Y. Deng, "D-AHP method with different credibility of information," Soft Computing, vol. 23, no. 2, pp. 683-691, 2019.

[38] J. Wang, L. Jie, and X. Zi, "Credibility evaluation of trust models based on fuzzy quantization and AHP in Ad hoc scene," in Proceedings of the International Conference on Advanced Communication Technology, Bikaner, India, August 2016.

[39] H. Guesmi, "FFED: a novel strategy based on fast entropy to detect attacks against trust computing in cloud," Cluster Computing, pp. 1-10, 2021.

[40] A. Sharma, P. Munjal, and H. Banati, "Entropy-based classification of trust factors for cloud computing," International
Journal of Grid and Utility Computing, vol. 11, no. 6, pp. 747-754, 2020.

[41] S. Nie, "A novel trust model of dynamic optimization based on entropy method in wireless sensor networks," Cluster Computing, vol. 22, no. 5, pp. 11153-11162, 2019.

[42] W. Shang and X. Xing, "ICS software trust measurement method based on dynamic length trust chain," Scientific Programming, vol. 2021, Article ID 6691696, 11 pages, 2021.

[43] Z. Yang, "Trust chain model and credibility analysis in software systems," in Proceedings of the 2020 5th International Conference on Computer and Communication Systems (ICCCS), Shanghai, China, February 2020.

[44] U. Jayasinghe, G. M. Lee, Á. MacDermott, and W. S. Rhee, "TrustChain: a privacy preserving blockchain with edge computing," Wireless Communications and Mobile Computing, vol. 2019, Article ID 2014697, 17 pages, 2019.

[45] M. V. Carvalho Fagundes, A. Cheles Keler, E. Oliveira Teles, S. A. B. Vieira de Melo, and F. G. Mendonca Freires, "Multicriteria decision-making system for supplier selection considering risk: a computational Fuzzy AHP-based approach," IEEE Latin America Transactions, vol. 19, no. 9, pp. 1564-1572, 2021.

[46] R. Fattahi and M. Khalilzadeh, "Risk evaluation using a novel hybrid method based on FMEA, extended MULTIMOORA, and AHP methods under fuzzy environment," Safety Science, vol. 102, pp. 290-300, 2018.

[47] Q. Wang, H. Wang, and Z. Qi, “An application of nonlinear fuzzy analytic hierarchy process in safety evaluation of coal mine," Safety Science, vol. 86, pp. 78-87, 2016.

[48] R. M. C. Ratnayake and K. Antosz, "Development of a risk matrix and extending the risk-based maintenance analysis with fuzzy logic," Procedia Engineering, vol. 182, pp. 602-610, 2017.

[49] S. Albery, D. Borys, and S. Tepe, "Advantages for risk assessment: evaluating learnings from question sets inspired by the FRAM and the risk matrix in a manufacturing environment," Safety Science, vol. 89, pp. 180-189, 2016.

[50] P. Li, Y. Ji, Z. Wu, and S.-J. Qu, "A new multi-attribute emergency decision-making algorithm based on intuitionistic fuzzy cross-entropy and comprehensive grey correlation analysis," Entropy, vol. 22, no. 7, p. 768, 2020.

[51] M. Deypir, "Entropy-based security risk measurement for Android mobile applications," Soft Computing, vol. 23, no. 16, pp. 7303-7319, 2019.

[52] Zifei, "A data-driven risk measurement model of software developer turnover," Soft Computing, vol. 24, no. 2, pp. 825-842, 2020. 